\title{
THE IT REVOLUTION AND SOUTHERN EUROPE'S TWO LOST DECADES
}

\author{
Fabiano Schivardi \\ LUISS University, EIEF
}

\author{
Tom Schmitz \\ Bocconi University and IGIER
}

\begin{abstract}
Since the middle of the 1990s, productivity growth in Southern Europe has been substantially lower than in other developed countries. We argue that this divergence was partly caused by inefficient management practices, which limited Southern Europe's gains from the IT Revolution. To quantify this effect, we build a multi-country general equilibrium model with heterogeneous firms and workers. In our model, the IT Revolution generates divergence for three reasons. First, inefficient management limits Southern firms' productivity gains from IT adoption. Second, IT increases the aggregate importance of management, making its inefficiencies more salient. Third, IT-driven wage increases in other countries stimulate Southern high-skill emigration. We calibrate our model using firm-level evidence, and show that it can account for 35\% of Italy's, $47 \%$ of Spain's and $81 \%$ of Portugal's productivity divergence with respect to Germany between 1995 and 2008. Counterfactual policy experiments show that subsidies to IT adoption or education cannot reduce this gap: only policies which directly tackle inefficient management are effective. (JEL: L23, O33)
\end{abstract}

\section{Introduction}

Since the middle of the 1990s, productivity growth in Southern Europe has been substantially lower than in other developed countries. The left panel of Figure 1 illustrates this by plotting aggregate productivity, measured as real GDP per hour worked (net of non-IT capital deepening), for six OECD countries 11 Between 1995

The editor in charge of this paper was Giovanni Peri.

Acknowledgments: We are grateful to Olegs Matvejevs, Paolo Mengano, Zijian Wang and Valeria Zurla for excellent research assistance. We thank Georg Duernecker and Salvatore Lo Bello for helpful discussions. We also thank seminar participants at Bocconi, Cattolica Milan, CSEF Naples, Helsinki Center of Economic Research, RWTH Aachen, EIEF, University of Genova, the 2018 Empirical Management Conference, the 25th CEPR European Summer Symposium in International Macroeconomics, the 2017 Madrid Workshop in Quantitative Macroeconomics and the 2016 ADEMU workshop on Job Creation, Job Destruction and Productivity Growth for their feedback. Schivardi is a Research Fellow at CEPR.

E-mail: fschivardi@luiss.it (Schivardi); tom.schmitz@unibocconi.it (Schmitz)

1. The data comes from the OECD Productivity Database, which decomposes growth in real GDP per hour worked into changes in total factor productivity (TFP), IT capital deepening and non-IT capital deepening. Our preferred measure of productivity growth is the sum of the two former components. This measure has the advantage to abstract from changes in the non-IT capital stock, while still taking into account the effect of IT capital. Online Appendix A provides further details on the data and replicates Figure 1 for changes in TFP (see Figure A.3. 
and 2015, productivity grew by only $0.1 \%$ per year in Italy and Spain and by $0.5 \%$ per year in Portugal, while it grew by $1.1 \%$ per year in Germany and by $1.4 \%$ per year in the United States.

Productivity growth

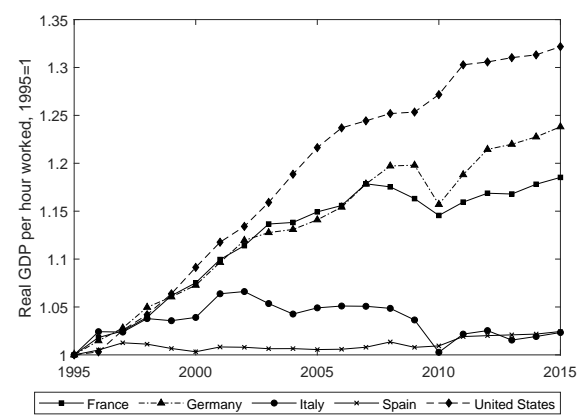

Growth in the real IT capital stock

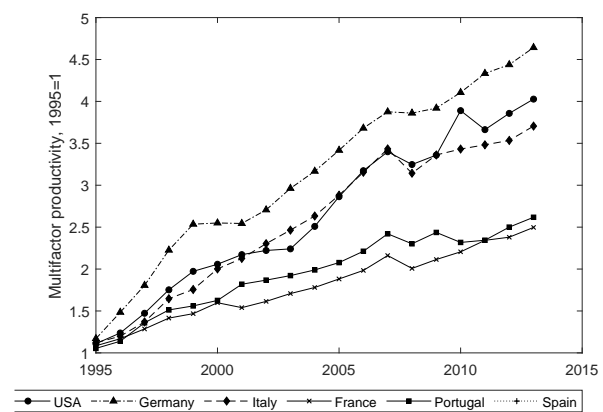

FIGURE 1. Productivity growth and IT capital across the OECD. Source: OECD and EU KLEMS. See Online Appendix A for further details.

The striking divergence of Southern Europe coincides with the rise of information technology (IT), which was a major driver of productivity growth in the leading economies (Fernald 2014, Gordon 2016) ${ }^{2}$ In Southern Europe, this IT Revolution made relatively little headway. The right panel of Figure 1 indicates that between 1995 and 2014, the real stock of IT capital increased by a factor of 4.6 in the United States and by a factor of 4 in Germany, but only by a factor of 1.5 in Italy, 2.6 in Portugal and 3.7 in Spain. This suggests two observations. First, the diffusion of IT in Southern Europe was limited. Second, even in countries which had somewhat faster growth in IT capital (such as Spain), this seems to have had a negligible impact on productivity. However, why did the IT Revolution have a lower impact in Southern Europe than elsewhere?

An extensive empirical literature has documented that IT adoption requires complementary changes in firm organization (Brynjolfsson and Hitt 2000) and that it induces higher productivity gains in better-managed firms (Garicano and Heaton 2010, Bloom et al. 2012). Building on the World Management Survey (WMS) developed by Bloom and Van Reenen (2007), we document that Southern European firms perform worse for a number of management efficiency measures. We also provide additional quantitative evidence for the complementarity of IT and efficient management practices, in line with the results of the earlier literature. This suggests that inefficient management practices may be responsible for Southern Europe's

2. In the 1980s, Robert Solow famously stated that "you can see the computer age everywhere, except in the productivity statistics" (Solow 1987). However, Byrne et al. (2013), Fernald (2014) and Gordon (2016) show that towards the middle of the 1990s, IT caused an acceleration of US productivity growth that lasted for at least a decade. US productivity has slowed down since, but even its low growth after 2005 substantially exceeds that of Southern Europe. 
divergence, as they lowered the productivity gains from IT adoption for Southern European firms and reduced their IT demand. This, in turn, depressed demand for the high-skilled labour necessary to operate the new technology and may have stimulated high-skilled emigration, another striking trend during the divergence period.

The main objective of our paper is to provide a quantitative model, disciplined by microeconomic evidence, to analyse these trends. We use this model to calculate the fraction of the total divergence between Northern and Southern Europe that can be explained by the interaction of inefficient management practices in the South and the arrival of the IT Revolution. The model considers two regions, called North and South. In each region, a continuum of workers choose whether to supply high or lowskilled labour in their home region or abroad. Their choices depend on education and migration costs, which are heterogeneous across workers, and on wages. Production is carried out by a continuum of firms, which produce differentiated nontradable goods under monopolistic competition. Firms pay an entry cost to draw an idiosyncratic productivity from an exogenous distribution, and then decide whether to exit or to stay in the market. In the latter case, they can produce with a basic technology or adopt more advanced technologies, such as management and IT. Advanced technologies increase productivity with respect to the basic one, but they also have higher fixed costs and require more high-skilled workers. Throughout, we assume that the North and the South are exactly identical, except for the fact that the efficiency of management practices (a parameter which determines the productivity increase of a firm adopting management) is lower in the South. We also assume that IT and efficient management are complements, in line with the literature and with our own empirical results. That is, IT increases firm productivity more in a region with more efficient management practices. In equilibrium, firms sort according to their idiosyncratic productivity draws: the firms with the highest draws adopt both management and IT, firms with intermediate draws adopt only management, firms with low draws produce with the basic technology, and the firms with the lowest draws exit.

To analyse the impact of the IT Revolution, we compare our model's equilibrium without IT (representing the situation before the IT Revolution) to an equilibrium with IT (representing the situation after the IT Revolution). Already before the IT Revolution, inefficient management practices lower management adoption and competitive pressure in the South. Thus, more firms are able to remain in the market, and the average firm is both smaller and less productive. Demand for highskilled labour is depressed, lowering the number of high-skilled workers and the skill premium, and leading some high-skilled workers to emigrate. As a result, output and aggregate productivity are lower in the South. In sum, the model shows that many long-run features of Southern European economies can be explained by a single factor, inefficient management.

The IT Revolution amplifies these pre-existing differences through three channels. First, the IT-management complementarity lowers Southern firm-level productivity gains from IT adoption. This directly lowers IT adoption rates and aggregate 
productivity growth $3^{3}$ Second, the IT Revolution increases the employment share of firms using management. This generates divergence through a composition effect. Southern firms are as efficient as their Northern counterparts for the basic technology, but less efficient for management. Thus, as the IT Revolution increases the aggregate importance of management, the Southern disadvantage becomes more salient. Third, the IT Revolution increases Northern high-skilled wages more than Southern ones. This increases high-skilled emigration, which amplifies productivity divergence by increasing the education costs of the marginal high-skilled worker in the South.

We use our model for a quantitative analysis of the IT Revolution's role for the divergence between Southern Europe and Germany between 1995 and 2008.4 We calibrate the most crucial parameters using evidence from the WMS, growth accounting, and our micro-level analysis on the link between management, IT and firm productivity. The remaining parameters are set to match a series of moments for Germany in 2008. In our baseline calibration, the IT Revolution increases productivity by $11.1 \%$ in Germany, $5.9 \%$ in Italy, $2.5 \%$ in Spain, and 3.4\% in Portugal. It therefore accounts for $35 \%$ of the Italian, $47 \%$ of the Spanish, and $81 \%$ of the Portuguese divergence with respect to Germany. Divergence is mainly driven by lower firmlevel productivity gains from IT adoption, compounded by lower adoption rates. The higher aggregate importance of management also makes a substantial contribution. High-skilled emigration is multiplied by a factor of three as a consequence of the IT Revolution, but this has a relatively small impact on aggregate productivity.

Finally, we use our model to evaluate a series of Southern European policy interventions aimed at reducing divergence. We show that subsidizing IT and management adoption actually increases divergence even further, with the negative impact falling most heavily on low-skilled workers. Subsidizing education also has negative effects, as it is effectively a transfer to the North, which reaps the benefits from the subsidy through high skilled workers' migration. These results should be taken with a grain of salt, as we abstract from market failures that might result in suboptimal levels of IT adoption or education. Nevertheless, they show that low IT adoption and low education levels are a symptom rather than the cause of low productivity growth in Southern Europe. Long-term policies should focus instead on the underlying cause that lowers firms' demand for IT and high-skilled labour, namely inefficient management. In particular, we show that a greater presence of multinational firms with superior management practices can bridge a part of the gap with respect to Northern Europe, especially if there are managerial spillovers from these firms to domestic ones.

3. Adoption rates are further depressed because (as a consequence of inefficient management) the average Southern firm is smaller than the average Northern firm, and thus less likely to pay the fixed cost of IT adoption.

4. Southern Europe was hit much harder by the financial crisis starting in 2008. This may have affected productivity and IT adoption for cyclical reasons that are not captured by our analysis. However, as a robustness check, we repeat our analysis for the full period 1995-2015. This yields similar results, as we discuss in greater detail in Section 4 
Our analysis is closely related to Bloom et al. (2012) and Pellegrino and Zingales (2017). Bloom et al.(2012) show that subsidiaries of US multinationals in Great Britain use IT more intensively and more efficiently than other firms operating in the country, and that this is due to their more efficient management practices. They conjecture that this finding may explain divergence between Europe and the United States since the middle of the 1990s, but do not provide a detailed quantitative assessment of this claim. Pellegrino and Zingales (2017) empirically test several hypotheses for the Italian slowdown, concluding that the most likely cause is the "familism and cronyism" of Italian firms, making them unable to benefit from the IT Revolution. Our main contribution with respect to these studies is to provide an analysis based on a general equilibrium model rather than relying on reduced-form regressions. We show that this difference matters quantitatively, because it allows us to take into account some crucial features such as firm heterogeneity and the endogeneity of IT adoption decisions. Moreover, our model emphasizes some divergence channels which have not been considered before, such as the increase in the aggregate importance of management or the role of high-skilled emigration.

Garicano (2015) has also stressed the role of IT for Southern Europe's slowdown, arguing that small firm size due to size-dependent regulations limited IT adoption. However, the evidence on size-dependent regulations is mixed: while Garicano et al. (2016) show that they matter in France, Schivardi and Torrini (2008) argue that their role in Italy is marginal. In our model, firm size is depressed because of inefficient management, and this further lowers IT adoption. Other studies have proposed different explanations for Southern Europe's divergence. For instance, Gopinath et al. (2017) argue that misallocation of capital inflows slowed down TFP growth in the manufacturing sector ${ }^{5}$ Our results are complementary to their findings. Indeed, we find that the IT Revolution does not account for all of Southern Europe's divergence. Thus, there must have been other drivers, misallocation of capital being one of them. Focusing on Italy, Daveri and Parisi (2010) have instead stressed the role of labour market reforms 6

More generally, our paper builds on the extensive literature on the IT Revolution (see, among many others, Stiroh 2002, Syverson 2011 and Akerman et al.2015). It also relates to a number of studies on the role of management efficiency for cross-country TFP differences (Guner et al. 2015, Akcigit et al. 2016, Bloom et al. 2016), which however do not consider IT. Finally, our model shares some similarities with Bustos

\footnotetext{
5. Related studies focusing on Italy (Calligaris 2015 Calligaris et al. 2016) or Spain Garcia-Santana et al. 2015) reach similar conclusions. They also show that the Southern European slowdown cannot be explained by its sectoral structure: productivity growth was low in virtually every sector, pointing to a more general common cause.

6. It has long been recognized that Southern Europe suffers from a number of institutional imperfections. However, in spite of these, it grew very rapidly between 1945 and 1995 . Thus, the later divergence must be due to a major change in the economic environment in the middle of the 1990s. In our theory, this change was the IT Revolution, which boosted the importance of management practices, while for Gopinath et al. (2017), it was the creation of the Euro, which led to capital inflows that were inefficiently allocated to low-productivity firms.
} 
(2011), who extends the classic Melitz (2003) framework by allowing firms to pay a fixed cost to increase their productivity.

The remainder of the paper is structured as follows. Section 2 presents some basic stylized facts on management practices, IT adoption and emigration in Southern Europe, including microeconometric evidence that will inform our calibration. Section 3 sets up and solves a model with firm and worker heterogeneity which identifies the main channels for divergence. Section 4 describes our calibration and the model's quantitative implications. Section 5 analyses a series of counterfactual policy interventions aimed at reducing divergence, and Section 6 concludes.

\section{Management Practices, IT and Emigration in Southern Europe}

Our analysis rests on two key assumptions: countries differ in the efficiency of firms' management practices, and efficient management practices and IT are complements. In this section, we provide evidence for both assumptions, quantify them, and discuss their implications for productivity growth and high-skilled migration.

\subsection{Management Practices}

While the importance of management for firm productivity has long been recognized, research on the subject has been constrained by the lack of quantitative evidence. In the last decade, however, measurement of management practices has greatly improved, particularly thanks to the World Management Survey (WMS), developed by Nick Bloom, Raffaella Sadun and John Van Reenen. The WMS covers more than 30 countries, and its baseline version, which we use in this paper, focuses on manufacturing firms of intermediate size (between 50 and 5000 employees). Data is collected in telephone interviews during which a trained interviewer asks plant managers about various management practices (for instance, the setting of goals, performance measurement, or human resource management), and then scores these on a scale ranging from 1 to 5 (lower scores indicating worse practices) $\square^{7}$ Following standard practice, we define a "management score" at the firm level as the arithmetic average of the scores for the single questions, standardized to have mean 0 and standard deviation 1 across the sample.

Panel A of Figure 2 plots the average value of this score for a set of OECD countries. This figure reveals substantial cross-country differences in management scores. In particular, Southern European countries such as Italy, Spain, Portugal and Greece have substantially lower scores than Northern European countries, the United States, Canada and Japan. This pattern could in principle be driven by composition effects. Indeed, Online Appendix Table A.1 shows that average firm size differs

7. The WMS is described in greater detail in Online Appendix A which also contains summary statistics for every country. We are grateful to Bloom, Sadun and Van Reenen for providing us with the nonanonymized version of the data. 

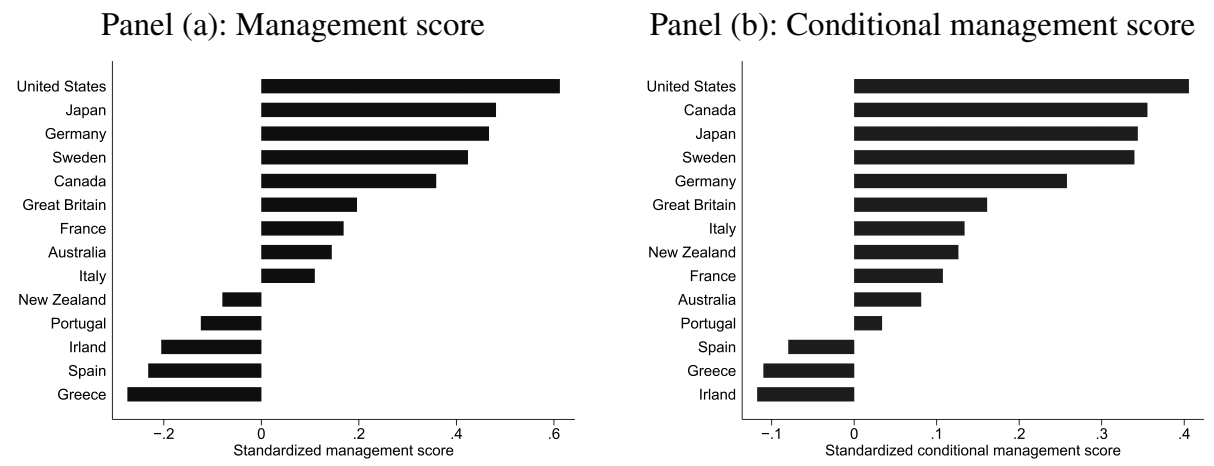

FIGURE 2. Management efficiency in OECD countries. Source: Authors' calculations based on WMS data. For details, see Online Appendix A The conditional score is the residual of a regression of firm management scores on sector fixed effects and the natural logarithm of employment.

substantially across countries, and larger firms might have higher scores. Countries also differ in terms of sectoral specialization. However, Panel B of Figure 2 reports average management scores after controlling for 20 two-digit sector fixed effects and for firm size (measured by employment). The pattern is very similar, suggesting that differences in management scores are not only driven by composition, but reflect some other country attributes.

A growing body of experimental and quasi-experimental studies show that differences in management scores matter, as better management practices have a causal impact on firm productivity $\left.\right|^{8}$ Reviewing the evidence, Bloom et al. (2016) conclude that a unit increase in the standardized management score increases firm productivity by around $10 \%$.

However, do these differences in management practices matter for Southern Europe's divergence? Figure 3 provides some preliminary evidence on this point. Panel A shows that before the IT Revolution, there was no correlation between management scores and productivity growth. However, Panel B shows that this changed radically around 1995, and a strong positive correlation emerged. Thus, inefficient management practices started to become a drag on growth with the beginning of the IT Revolution. This supports our story, namely that IT and management are complements and that this can explain Southern European divergence after the start of the IT Revolution in 1995.9

Our productivity measure shown in Figure 3 (real GDP per hour worked, net of non-IT capital deepening) can be decomposed into the relative contributions of IT capital deepening and TFP. This decomposition shows that most of the cross-country

8. Bloom et al. (2013) and Bruhn et al. (2018) set up field experiments in India and Mexico, randomly selecting entrepreneurs into managerial training. Giorcelli (2016) exploits a natural experiment due to an unexpected budget cut of a program within the Marshall plan offering management-training trips to the United States for Italian managers.

9. We define the IT Revolution as the IT-driven acceleration in frontier (US) productivity growth. Byrne et al. (2013) date the start of this event in 1995, Fernald (2014) and Gordon (2016) in 1996. 
Panel (a): 1985-1995

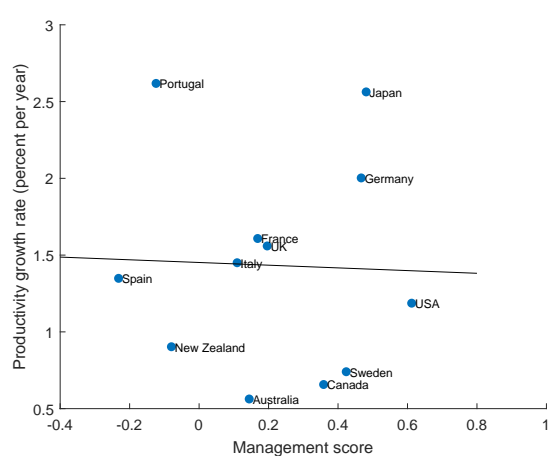

Panel (b): 1995-2008

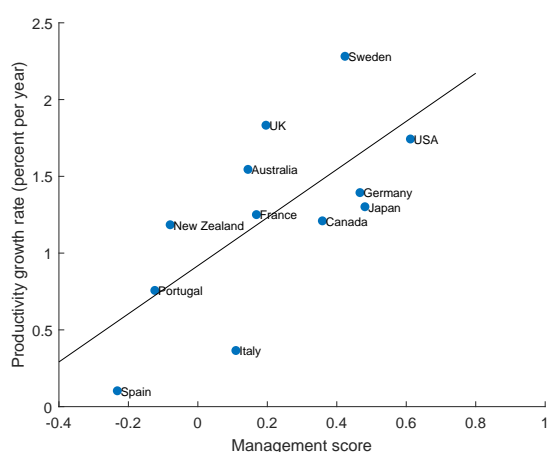

FIGURE 3. Management scores and productivity growth before and after the IT Revolution. Source: OECD, WMS. Productivity growth is growth in real GDP per hour worked net of non-IT capital deepening (see Figure 11. These graphs omit Greece (which has no productivity data) and Ireland (see discussion in Online Appendix A.

differences in productivity growth are explained by TFP (see Online Appendix A. At first sight, this may seem to indicate that the IT Revolution cannot be responsible for divergence. However, it is well known that standard growth accounting methods do not fully capture the contribution of IT capital to productivity growth: they miss IT-induced investments in intangible capital and changes in firm organization, which often occur with considerable lags (Basu and Fernald 2008; Brynjolfsson, Rock, and Syverson 2018b), as well as externalities and spillovers (Pellegrino and Zingales 2017). Furthermore, TFP growth includes TFP growth in IT-producing industries, which should arguably be attributed to the IT Revolution. For all of these reasons, the complementarity between management practices and IT will show up in TFP, and can potentially explain the large cross-country differences in TFP growth.

In the next section, we discuss the existing evidence for this complementarity, and provide additional quantitative results that will inform our model's calibration.

\subsection{Complementarities between Management and IT}

2.2.1. The Existing Empirical Evidence. An extensive empirical literature on the IT Revolution argues that IT needed organizational capital investments to develop its full potential (Brynjolfsson and Hitt 2000). Even more importantly, it shows that efficient management practices increase the productivity gains from IT adoption. For instance, Bresnahan et al. (2002) use a panel dataset for the US to show that the productivity impact of IT is largest in firms with high levels of human capital or a decentralized work organization. Garicano and Heaton (2010) argue that IT investments in US police departments improved productivity only if they were "complemented with particular organizational and management practices". Bloom et al.(2012) show that subsidiaries of US multinationals in Great Britain use IT more and more efficiently than local firms, 
and attribute this to their superior management practices. They also provide evidence of IT-management complementary using a panel of European firms.

These findings suggest that countries with less efficient management practices should have benefited less from the IT Revolution, in line with the evidence shown in Figure 3. In the next sections, we present some stylized facts on IT adoption and regression evidence for its productivity impact which further support this claim.

2.2.2. IT Adoption across Europe. To document IT adoption patterns, we rely on the 2014 wave of the European "Community survey on ICT usage and e-commerce in enterprises". This survey, coordinated by Eurostat and run by national statistical offices, is based on a representative sample of firms with more than 10 employees, stratified by sector, size and geographical area. We obtained access to the micro data for Germany and Italy, the two largest economies in Northern and Southern Europe 10 The survey covers around 19.000 firms in Italy and 7.500 firms in Germany.

The generic term "IT" refers to a large array of different technologies, including both hardware and software. Table 1 shows adoption rates for four different measures of IT, indicating the fraction of Italian and German firms that employ IT specialists (that is, workers for whom IT and information systems management represent the main occupation), or use software for enterprise resource planning (ERP), customer relations management (CRM) and supply-chain management (SCM). Italian adoption rates are lower for all four measures. Part of this is due to a composition effect: smaller firms are less likely to adopt IT, and the average Italian firm is smaller than the average German one ${ }^{11}$ However, for most technologies, there are also substantial differences within size classes.

Together with the evidence on IT capital in Figure 1, these adoption rates show that IT is less diffused in Southern Europe. A priori, this could be due to problems relating to IT supply, such as a low supply of IT-savvy workers or deficient infrastructure. However, the survey provides some evidence against these explanations. Indeed, it indicates that only $30 \%$ of Italian firms that wanted to hire IT specialists reported problems in doing so, while the corresponding number for Germany was $52 \%$. Furthermore, roughly all firms from both countries had access to the internet in 2014, at comparable speeds (see Table A.5 in Online Appendix A).

Thus, low IT diffusion in Southern Europe seems to be due to low IT demand rather than low IT supply. This is consistent with our hypothesis: if IT and efficient management are complements, then less efficient management practices lower the productivity gains from IT and therefore firms' adoption incentives. In the next section, we provide more evidence for this crucial claim.

10. We focus only on these two countries because access to the data requires a formal application at each national statistical office, with access rules differing by countries. Further details on the survey are given in Online Appendix A

11. This may be due to fixed adoption costs, as in our model. Other studies also find a positive correlation between size and IT adoption (see Fabiani et al. (2005) for Italy and Bayo-Moriones and Lera-López (2007) for Spain). 
TABLE 1. Adoption rates for various IT technologies in Italy and Germany.

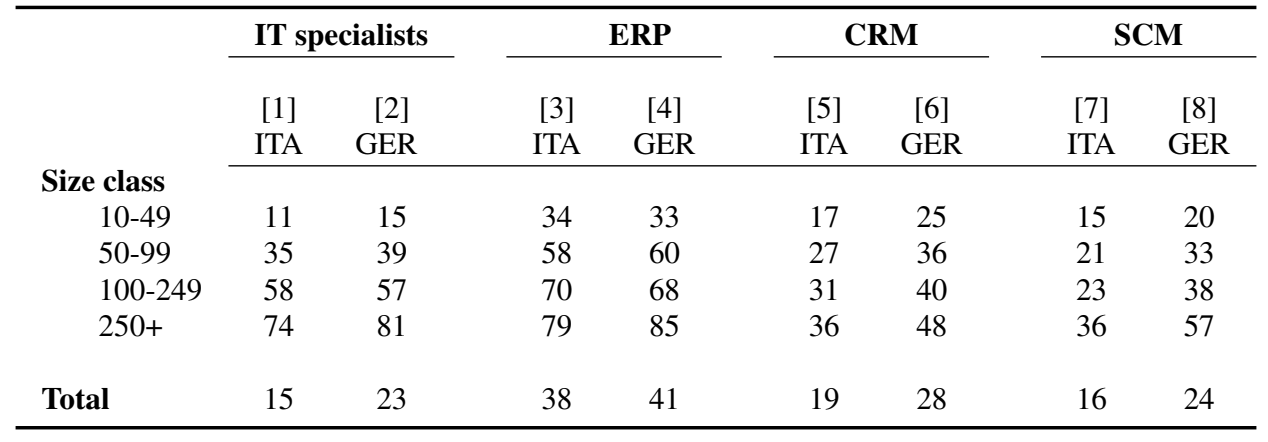

Source: Research Data Centre of the Federal and Regional Statistical Offices, "Nutzung von Informations - und Kommunikationstechnologien (IKT) in Unternehmen 2014" (Germany), ISTAT (Italy), own calculations. All numbers shown correspond to the percentage of firms of a given size class which use the indicated technology. These statistics use survey weights. For clarity, we report unconditional summary statistics, but all results are confirmed when we control for sectoral and geographical dummies.

2.2.3. Productivity Effects of Management and IT Adoption . To study the complementarity between management practices and IT, we construct a firm-level dataset that matches three sources of information. To compute productivity, we use accounting data from the Bureau Van Dijk database. Data on management practices are from the WMS discussed above. Finally, IT adoption indicators are from Harte-Hanks (HH in what follows), a US consulting firm which surveys production sites to assess adoption rates for a large class of hardware and software items 12 We concentrate on software adoption in our analysis, but our results turn out to be remarkably similar to the ones of Bloom et al. (2012), who study the complementarity between management practices and hardware adoption (measuring IT as computers per worker).

$\mathrm{HH}$ classifies software into 14 different categories (including ERP, SCM, Communication software, Office applications, Storage, Security etc.). For each item, $\mathrm{HH}$ gives the number of production sites that use the software, and we define a firmlevel adoption rate as the percentage of sites of the firm which use the software. We use two measures of IT adoption. Our main measure is the simple average of adoption rates for all 14 software categories, which is intended to capture the firm's overall IT adoption. Furthermore, we also consider a summary indicator for the adoption of ERP software. This software is closely related to human resources management, which has been identified as an area in which IT had a particularly large impact. The survey reports both a general ERP software and specific applications within this general category, such as Supply Chain Management or Sales Force Management. We construct an indicator for the general software and one for the specific ones, and take the average of the two as our summary measure.

12. We thank Friedrich Kreuser for systematizing the large and complex HH database and sharing it with us. Further information on the datasets is provided in Online Appendix A 
The three datasets have different time structures. The accounting data are available annually. Firms in the WMS survey can be surveyed more than once: approximately half of the firms have been surveyed once, $34 \%$ twice, and $16 \%$ three times or more. To maximise coverage, we take the average value of the management score across surveys as the (fixed) indicator of managerial efficiency for each firm. HH surveys firms repeatedly, but with gaps. To maximise coverage and to take into account the trend in the diffusion of IT, we fill the gaps by taking a linear interpolation at the firm level. We end up with a sample of around 10,500 firm-year observations, corresponding to 1,361 firms. Observations are from nine OECD countries: France (with 1,128 observations), Germany (1,011), the United Kingdom (2,278), Italy (1,727), Poland (474), Portugal (503), Spain (578), Sweden (1,209) and the United States (1,732). The average value for our overall software indicator is 0.32 (s.d. 0.21 ), while it is 0.43 (s.d. 0.33) for the ERP indicator.

We run the following regression:

$$
\begin{aligned}
\ln \left(\frac{V A_{i j k t}}{L_{i j k t}}\right)= & \beta_{1} I T_{i j k t}+\beta_{2} I T_{i j k t} \cdot M A N_{i j k}+\beta_{3} M A N_{i j k} \\
& +\beta_{4} \ln \left(\frac{K_{i j k t}}{L_{i j k t}}\right)+\beta_{5} \ln \left(L_{i j k t}\right)+\alpha_{j}+\alpha_{k}+\alpha_{t}+v_{i j k t},
\end{aligned}
$$

where $V A_{i j k t} / L_{i j k t}$ is value added per worker of firm $i$ in country $j$ and sector $k$ at time $t, I T_{i j k t}$ is the indicator of IT adoption, $M A N_{i j k}$ is the (standardized) management score, $K_{i j k t} / L_{i j k t}$ is capital per worker, and $L_{i j k t}$ is the number of workers. We always include country, sector (two-digit SIC) and time dummies, and cluster standard errors at the firm-level.

The first column of Table 2 shows the results of the specification for the general measure of IT adoption. We find that labour productivity is positively related to IT, and that firms with higher management scores are more productive, consistent with the evidence reviewed above. More importantly, the interaction between the management score and IT adoption is positive and significant at the $10 \%$ level. To give a sense of the size of the effect, recall that the standard deviation of the management score is 1 and that of IT adoption is 0.21 . Therefore, increasing IT adoption by one standard deviation is related to a $1.9 \%$ higher productivity increase in a firm with a one standard deviation higher management score. Finally, labour productivity increases with capital intensity and decreases mildly with size.

Needless to say, these estimates cannot be interpreted causally: IT adoption is likely to be related to unobserved heterogeneity not accounted for by the management score. As a further control, we thus introduce firm fixed effects in Column [2]. Then, we can no longer estimate the coefficient of the management score, as the latter does not vary within-firm. The coefficient on IT adoption is now essentially zero, while the interaction with the management score decreases from 0.091 to 0.067 , but becomes significant at the $5 \%$ level. Thus, our results cannot be explained by some fixed firm attribute: when a firm adopts more IT, its productivity gains are larger if it has more efficient management practices. 
TABLE 2. Productivity, management and IT.

\begin{tabular}{|c|c|c|c|c|}
\hline & \multicolumn{4}{|c|}{ IT adoption indicator } \\
\hline & [1] & [2] & [3] & [4] \\
\hline & & & & \\
\hline IT & $\begin{array}{l}0.085^{*} \\
(0.050)\end{array}$ & $\begin{array}{l}-0.000 \\
(0.032)\end{array}$ & $\begin{array}{c}0.034 \\
(0.034)\end{array}$ & $\begin{array}{c}0.003 \\
(0.023)\end{array}$ \\
\hline IT·Man & $\begin{array}{l}0.091^{*} \\
(0.055)\end{array}$ & $\begin{array}{c}0.067 * * \\
(0.033)\end{array}$ & $\begin{array}{c}0.081 * * \\
(0.033)\end{array}$ & $\begin{array}{c}0.055^{* * *} \\
(0.026)\end{array}$ \\
\hline Man & $\begin{array}{c}0.055^{* *} \\
(0.025)\end{array}$ & & $\begin{array}{c}0.049 * * \\
(0.023)\end{array}$ & \\
\hline$\frac{K}{L}$ & $\begin{array}{c}0.233^{* * * *} \\
(0.019)\end{array}$ & $\begin{array}{c}0.130 * * * \\
(0.016)\end{array}$ & $\begin{array}{c}0.234 * * * \\
(0.019)\end{array}$ & $\begin{array}{c}0.130 * * * \\
(0.016)\end{array}$ \\
\hline$L$ & $\begin{array}{c}-0.040^{*} \\
(0.021)\end{array}$ & $\begin{array}{c}-0.207 * * * \\
(0.036)\end{array}$ & $\begin{array}{c}-0.041^{*} \\
(0.021)\end{array}$ & $\begin{array}{c}-0.207 * * * \\
(0.036)\end{array}$ \\
\hline Firm FE & NO & YES & NO & YES \\
\hline Observations & 10,479 & 10,260 & 10,479 & 10,260 \\
\hline$R$-squared & 0.428 & 0.813 & 0.428 & 0.813 \\
\hline
\end{tabular}

Note: The dependent variable is value added per worker. All regressions include country, sector and year fixed effects. Even columns also include firm fixed effects. Standard errors clustered at the firm level in parentheses. ${ }^{*}: p<0.10,{ }^{* *}: p<0.05,{ }^{* * *}: p<0.01$.

In Columns [3] and [4], we repeat the same regressions using our measure of ERP adoption. Results are even stronger than those for the general indicator, consistent with the notion that management-IT complementarities are particularly important for ERP software. In particular, we find that increasing ERP adoption by one standard deviation is related to a $2.7 \%$ higher productivity increase in a firm with one standard deviation higher management score. Overall, our evidence thus supports the assumption that efficient management practices and IT adoption are complements.

\subsection{High-Skill Migration}

Next, we briefly discuss another striking trend in Southern Europe over the last two decades, high-skilled emigration. Table 3 illustrates high-skilled migration patterns using the first and the latest edition of the Database on Immigrants in OECD countries (DIOC), referring to the years 2000 and 2010. High skilled individuals are those with a tertiary degree. We restrict our attention to migration between Southern Europe (Italy, Spain and Portugal) and the "North", which we define as the rest of the G7, in order to abstract from developing countries. We focus on flows rather than stocks, and therefore only consider recent migrants, who arrived in their country of residence at most five years before the survey.

In 2000, net high-skilled migration was already negative for Southern Europe: there were around 8000 more Southern Europeans leaving for the North than Northerners arriving in Southern Europe. These numbers were however relatively small, both with respect to the overall and the high-skilled population. During the 2000s, there has been a massive acceleration: in 2010, the net outflow of high-skilled people from Southern 
TABLE 3. High-skilled migration flows between Southern Europe and the North.

\begin{tabular}{lcccc|ccc}
\hline & & \multicolumn{3}{c}{2000} & \multicolumn{3}{c}{2010} \\
\cline { 3 - 8 } & & absolute & $\%$ of high-sk. & $\%$ of pop. & absolute & $\%$ of high-sk. & \% of pop. \\
\hline \multirow{3}{*}{ North } & Immigration & 56452 & $0.06 \%$ & $0.01 \%$ & 132196 & $0.12 \%$ & $0.03 \%$ \\
& Emigration & 48838 & $0.06 \%$ & $0.01 \%$ & 70408 & $0.06 \%$ & $0.02 \%$ \\
& Net & 7614 & $0.01 \%$ & $0.00 \%$ & 61788 & $0.05 \%$ & $0.02 \%$ \\
\multirow{4}{*}{ Southern Europe } & Immigration & 48838 & $0.48 \%$ & $0.06 \%$ & 70408 & $0.45 \%$ & $0.08 \%$ \\
& Emigration & 56452 & $0.55 \%$ & $0.06 \%$ & 132196 & $0.84 \%$ & $0.15 \%$ \\
& Net & -7614 & $-0.07 \%$ & $-0.01 \%$ & -61788 & $-0.39 \%$ & $-0.07 \%$ \\
\hline
\end{tabular}

Source: OECD and authors' calculations. Migrants are persons who arrived in their country of residence at most five years before the survey, and defined with respect to the two regions. Thus, immigrants in the North only refer to Southern Europeans, ignoring all other nationalities. For further details, see Online Appendix A

Europe was 8 times higher in absolute numbers and 5 times higher as a percentage of the high-skilled population. Importantly, this outflow is not just driven by the Eurozone crisis: our data for 2010 refer to migration flows for 2006-2010, and the crisis-driven outflows only started at the very end of this period ${ }^{13}$ In our model, we argue that this acceleration can be interpreted as an endogenous consequence of Southern Europe's divergence, as skilled workers were attracted by higher wages in countries exploiting the IT Revolution more successfully.

\subsection{Origins and Stability of Management Practices}

The stylized facts presented in this section are the main building blocks of our argument. In the next section, we develop a model that ties them all together and allows for a quantitative analysis. To keep our analysis tractable, we will make two simplifying assumptions regarding management practices, which it is useful to discuss in some detail.

First, we abstract from within-country variation in management practices. While there is substantial within-country dispersion in the data, our model (which builds on the standard Melitz (2003) framework) already assumes that firms are heterogeneous with respect to their idiosyncratic productivity. Adding a second layer of firm heterogeneity makes the analysis substantially more complicated, and arguably would only have a second-order effect on our results. Indeed, in Online Appendix A, we show that the distribution of management scores is similar across countries, so that focusing on its mean accounts for the most important cross-country differences.

13. In Italy, the crisis led to a further acceleration of outflows in 2010 (Anelli and Peri 2017). In Spain, where a large boom between 1995 and 2007 triggered an immigration wave, net outflows started around 2012 (Izquierdo et al. 2015). Accordingly, Table A.4 in Online Appendix A shows that the emigration dynamics until 2010 are mainly driven by Italy and Portugal. The Italian brain drain is further analysed in Becker et al. (2004), Anelli and Peri (2017) and Anelli et al. (2017). 
Second, and more importantly, we assume that cross-country differences in management practices are exogenous and constant over time. This is of course a strong assumption. However, research on the determinants of management practices is still in its early stages, and no clear consensus has yet emerged. Contributing to this debate is beyond the scope of our paper. We instead take differences in management practices as given and focus on their implications during the IT Revolution. Nevertheless, given their importance for our argument, we will further discuss possible determinants of management practices both theoretically, by formulating a stylized microfoundation for them in our model, and empirically, by reviewing the most recent literature in Section 5.4.

Furthermore, we note that there is some evidence for the stability of management practices over time. Figure A.2 in Online Appendix A plots the evolution of average WMS scores for seven OECD countries between 2002 and 2014. It shows that crosscountry differences in management practices have been quite stable: with the potential exception of Portugal, no country shows a significant time trend. While the WMS data was first collected in 2002, there is also some evidence that differences in management practices have existed over a much longer time horizon. For instance, Giorcelli (2016) quotes a 1949 report of the US Bureau of Labor Statistics stressing the low quality of Italian firms' management practices. She then shows that firms whose managers were treated with managerial training experienced long-lasting productivity improvements with respect to untreated firms, suggesting that such practices are persistent even at the firm level.

\section{A Model of the IT Revolution}

We build a simple general equilibrium model of IT adoption. The model analyses two regions which only differ with respect to their management efficiency, and compares them in an equilibrium without IT (before the IT Revolution), and in an equilibrium with IT (after the IT Revolution).

\subsection{Assumptions}

3.1.1. Workers. We assume that the world is composed of a continuum of infinitesimally small countries of two types, Northern $(N)$ and Southern $(S)$. As assumptions are symmetric across countries, we drop country superscripts whenever this does not cause confusion. Each country is populated by a unit mass of workers who consume a unique final good and do not experience disutility from labour supply.

Workers have heterogeneous types $j$, indexed on $[0,1]$, and need to make an occupational choice. A worker of type $j$ can supply either one unit of lowskilled labour or $j^{v_{1}}$ units of high-skilled labour if she stays in her home country. Alternatively, she can supply $j^{v_{1}+v_{2}}$ units of high-skilled labour if she emigrates to 
another country. Low-skilled workers cannot emigrate 14 Note that both education (that is, becoming high-skilled) and emigration reduce the worker's effective labour supply. The level of this cost is pinned down by the worker's type and by the positive parameters $v_{1}$ and $v_{2}$.

3.1.2. Firms and Technologies. In each country, the final good is assembled by a continuum of perfectly competitive firms from a mass $M$ of nontradable intermediates, with the production function

$$
Y=\left(\int_{0}^{M} y(i)^{\frac{\varepsilon-1}{\varepsilon}} d i\right)^{\frac{\varepsilon}{\varepsilon-1}}, \quad \text { with } \varepsilon>1 .
$$

Intermediates are produced under monopolistic competition. A firm can enter the market by employing $f_{E}$ units of high-skilled labour ${ }^{15}$ Once it has paid this entry cost, it receives a monopoly for the production of one intermediate $i$ with idiosyncratic productivity $A(i)$, drawn from an exogenous cumulative distribution function $G$. The exogenous productivity distribution is a Pareto distribution with minimum value 1 and shape parameter $k>\varepsilon-1$, so that $G(A)=1-A^{-k}$. This distributional assumption is empirically realistic (see Chaney 2008; Melitz and Redding 2014 and Geerolf 2017) and has convenient analytical properties which improve the model's tractability.

Upon learning its productivity draw, the firm decides whether to exit the market or to produce. In the latter case, it needs to choose its technology among three alternatives, ranging from a basic technology to two advanced ones. Advanced technologies increase firm productivity, but also have adoption costs.

The basic technology only uses low-skilled labour and allows the firm to produce with the production function $y(i)=A(i) l(i)$, where $l(i)$ stands for the units of lowskilled labour hired for production. It also entails a fixed cost of production of $f$ units of low-skilled labour.

Alternatively, the firm can decide to use management, the first advanced technology. This has a fixed adoption cost of $f_{M}$ units of high-skilled labour (on top of the fixed cost of production), and allows the firm to hire high-skilled managers which supervise production and increase its efficiency. We assume that firms need to hire $1 / \eta$ units of high-skilled labour for every unit of low-skilled production labour, and that this increases their productivity by a factor $\exp \left(\alpha_{0}+\alpha_{1} \xi\right)$. $\xi$ is a parameter measuring the

14. Empirical evidence suggests that high-skilled workers are more mobile than low-skilled ones (Wozniak 2010). Historically, Southern Europe had high emigration rates for low-skilled workers. However, the DIOC database described in the previous section shows that low-skill emigration from Southern Europe to the North increased by just $24 \%$ between 2000 and 2010, while high-skill emigration increased by $134 \%$. We therefore focus on high-skilled emigration in our baseline analysis, but briefly analyse low-skilled emigration in Section 4 (see Footnote 35 .

15. Assuming that entry requires high-skilled labour reflects the fact that firm creation generally involves some high-skilled services (financing, administrative registration etc.). However, this assumption is not crucial for our main results, which would be unchanged if entry required low-skilled labour. 
efficiency of management practices, while $\alpha_{0}$ and $\alpha_{1}$ are two positive parameters which determine the elasticity of firm productivity with respect to management efficiency. Throughout our analysis, we assume that the only difference between Northern and Southern countries is that Northern countries have more efficient management practices, i.e., $\xi^{N}>\xi^{S}$. Therefore, management adoption raises firm productivity in both regions, but more so in the North than in the South. As noted previously, we consider management efficiency $\xi$ as an exogenous primitive in our analysis. However, Section B.2 in the online appendix lays out a stylized model, building on Akcigit et al. (2016), which shows how these differences can be microfounded by differences in human capital, trust, family values or judicial institutions.

Finally, firms can also adopt IT, the second advanced technology. IT has a fixed adoption cost of $f_{I T}$ units of high-skilled labour and raises firm productivity by a factor $\exp \left(\mathbb{1}_{M}\left(\alpha_{2} \varphi+\alpha_{3} \xi \varphi\right)\right)$, where $\mathbb{1}_{M}$ equals 1 if the firm uses management and 0 otherwise. The parameter $\varphi$ represents the current state of IT technology, while the parameters $\alpha_{2}$ and $\alpha_{3}$ determine how IT affects firm productivity. Note that IT does not improve productivity in firms without management, and that an IT-adopting firm gets a higher productivity increase in a region with more efficient management practices (i.e., the production function is $\log$-supermodular in the parameters $\xi$ and $\varphi$ ). These two crucial assumptions capture the complementarities between IT and management documented in Section 2.2. Summarizing, the production function is

$y(i)=\left\{\begin{array}{lr}A(i) l(i) & \text { with the basic technology } \\ A(i) e^{\alpha_{0}+\alpha_{1} \xi} \min (\eta m(i), l(i)) & \text { with management and without IT, } \\ A(i) e^{\alpha_{0}+\alpha_{1} \xi+\alpha_{2} \varphi+\alpha_{3} \xi \varphi} \min (\eta m(i), l(i)) & \text { with management and IT }\end{array}\right.$

where $m(i)$ stands for the units of high-skilled managerial labour employed by firm $i$ and where we have already used the fact that no firm ever adopts IT without adopting management.

In our model, countries do not trade, but only interact through migration. For simplicity, we assume that there are only a discrete number of Southern countries, so that the South is arbitrarily small with respect to the North. Thus, Southern emigration does not affect Northern wages, which is plausible for our application, as emigration from Southern Europe was arguably too small to significantly affect wages in other OECD countries. This completes the model's assumptions, and we can now solve for its equilibrium.

\subsection{Equilibrium Conditions}

To solve for the equilibrium, we conjecture that high-skilled and low-skilled wages are both higher in the North than in the South. This implies that Northern workers do not emigrate, and we can solve for the Northern equilibrium ignoring migration. Then, we use Northern wages as parameters to solve for the Southern equilibrium, and verify that wages are indeed lower in the South. 


\subsubsection{Equilibrium Conditions for Northern Countries.}

Worker Decisions. In every Northern country, the income of worker $j$ is given by $w_{L}$ if she supplies low-skilled labour and $j^{\nu_{1}} w_{H}$ if she supplies high-skilled labour, where $w_{H}$ and $w_{L}$ denote the wage rates for one unit of high and low-skilled labour. Thus, a low-skilled worker earns an entire low-skilled wage rate, while a high-skilled worker earns just a fraction of the high-skilled one, as she spends some of her labour endowment in education. This implies that in equilibrium, there is a skill premium: $w_{H}$ must exceed $w_{L}$ to incentivise some workers to become high-skilled.

It is easy to show that there exists a cut-off type $j^{*}$ such that all workers with types between 0 and $j^{*}$ become low-skilled and all workers with types between $j^{*}$ and 1 become high-skilled. The cut-off is defined by

$$
j^{*}=\left(\frac{w_{L}}{w_{H}}\right)^{\frac{1}{\nu_{1}}} .
$$

Thus, the supply of high and low-skilled labour is

$$
L=j^{*}=\left(\frac{w_{L}}{w_{H}}\right)^{\frac{1}{\nu_{1}}} \text { and } H=\int_{j^{*}}^{1} j^{\nu_{1}} d j=\frac{1}{1+v_{1}}\left(1-\left(\frac{w_{L}}{w_{H}}\right)^{\frac{1+\nu_{1}}{\nu_{1}}}\right) \text {, }
$$

and we can express the relative supply of high-skilled labour as a simple increasing function of the skill premium $w_{H} / w_{L}$ :

$$
\frac{H}{L}=\frac{1}{1+v_{1}}\left(\frac{w_{H}}{w_{L}}\right)^{\frac{1}{v_{1}}}\left(1-\left(\frac{w_{H}}{w_{L}}\right)^{-\frac{1+v_{1}}{v_{1}}}\right) .
$$

Price Setting and Profits. Cost minimization by final good producers implies that demand for any intermediate variety $i$ is given by

$$
y(i)=p(i)^{-\varepsilon} Y,
$$

where we have normalized the price of the final good to 1 in each country ${ }^{16}$ Then, standard arguments show that each intermediate firm optimally chooses to set a price which is a mark-up $\varepsilon /(\varepsilon-1)$ over its marginal cost. The marginal cost of a firm using the basic technology is $w_{L} / A{ }^{17}$ Firms with management hire $1 / \eta$ units of high-skilled management labour for every unit of production labour. Thus, their marginal cost of production if they do not adopt IT is

$$
\frac{w_{L}+\frac{w_{H}}{\eta}}{A \exp \left(\alpha_{0}+\alpha_{1} \xi\right)}
$$

16. Note that we can normalize price levels independently in every country because there is no trade.

17. For simplicity, we drop the firm index $i$ from now on. 
If they do adopt IT, it becomes

$$
\frac{w_{L}+\frac{w_{H}}{\eta}}{A \exp \left(\alpha_{0}+\alpha_{1} \xi+\alpha_{2} \varphi+\alpha_{3} \xi \varphi\right)}
$$

Combining price choices with the demand function in Equation (7), the profits of a firm that paid the entry cost and learned its productivity are therefore

$$
\pi(A)=\left\{\begin{array}{lr}
\left(\frac{A}{w_{L}}\right)^{\varepsilon-1} B-f w_{L} & \text { with the basic technology } \\
\tilde{\xi}\left(\frac{A}{w_{L}}\right)^{\varepsilon-1} B-f w_{L}-f_{M} w_{H} & \text { with management and without IT }, \\
\tilde{\varphi}\left(\frac{A}{w_{L}}\right)^{\varepsilon-1} B-f w_{L}-\left(f_{M}+f_{I T}\right) w_{H} & \text { with management and IT }
\end{array}\right.
$$

where

$$
\begin{aligned}
B & \equiv \frac{1}{\varepsilon-1}\left(\frac{\varepsilon}{\varepsilon-1}\right)^{-\varepsilon} Y, \\
\tilde{\xi} & \equiv\left(\frac{\exp \left(\alpha_{0}+\alpha_{1} \xi\right)}{1+\frac{w_{H}}{\eta w_{L}}}\right)^{\varepsilon-1}, \\
\tilde{\varphi} & \equiv\left(\frac{\exp \left(\alpha_{0}+\alpha_{1} \xi+\alpha_{2} \varphi+\alpha_{3} \xi \varphi\right)}{1+\frac{w_{H}}{\eta w_{L}}}\right)^{\varepsilon-1} .
\end{aligned}
$$

Production and Technology Adoption. Upon learning their idiosyncratic productivity draw $A$, firms must decide whether to exit or to produce with one of the three available technologies. While the profits from exit are 0 (abstracting from the sunk entry cost), the profits from the other options are given by Equation (8). Production, management and IT adoption all increase firms' variable profits, but have a fixed cost. Therefore, low-productivity firms, which have lower variable profits, are less likely to produce and to adopt technology than high-productivity firms. It is easy to show that firms sort according to their idiosyncratic productivity, so that their choices can be summarized by three cut-offs holding $1 \leq A^{*} \leq A_{M}^{*} \leq A_{I T}^{*}$. Firms with draws lower than $A^{*}$ exit the market, firms with draws between $A^{*}$ and $A_{M}^{*}$ produce with the basic technology, firms with draws between $A_{M}^{*}$ and $A_{I T}^{*}$ produce with management, but without IT, and firms with draws higher than $A_{I T}^{*}$ produce with both management and IT. For simplicity, we impose parameter restrictions which ensure $1<A^{*}<A_{M}^{*}$, that is, that there are always some firms which do not produce, and some firms which produce without management ${ }^{18}$ Then, the exit cut-off is

$$
A^{*}=w_{L}\left(\frac{f w_{L}}{B}\right)^{\frac{1}{\varepsilon-1}} .
$$

18. This configuration is empirically realistic: in the data, some firms exit shortly after their entry, and some firms produce without management. In the main text, we furthermore focus on equilibria in which $A_{M}^{*}$ is finite (that is, in which at least some firms adopt management). All derivations and parameter conditions can be found in Online Appendix $B$ 
For management and IT cut-offs, we need to distinguish two cases. When $(\tilde{\varphi}-\tilde{\xi}) f_{M}<(\tilde{\xi}-1) f_{I T}$,

$$
A_{M}^{*}=w_{L}\left(\frac{f_{M} w_{H}}{(\tilde{\xi}-1) B}\right)^{\frac{1}{\varepsilon-1}} \quad \text { and } \quad A_{I T}^{*}=w_{L}\left(\frac{f_{I T} w_{H}}{(\tilde{\varphi}-\tilde{\xi}) B}\right)^{\frac{1}{\varepsilon-1}}
$$

Otherwise, we have

$$
A_{M}^{*}=A_{I T}^{*}=w_{L}\left(\frac{\left(f_{M}+f_{I T}\right) w_{H}}{(\tilde{\varphi}-1) B}\right)^{\frac{1}{\varepsilon-1}} .
$$

Intuitively, if IT leads to a large productivity increase and/or its fixed cost is low, the second case applies and all firms with management also adopt IT. These cut-offs pin down the shares of producing firms using management and IT. Recall that the probability that a producing firm has an idiosyncratic productivity draw higher than $A$ is given by

$$
\frac{1-G(A)}{1-G\left(A^{*}\right)}=\left(\frac{A^{*}}{A}\right)^{k}
$$

Hence it follows that the share $s_{M}$ of firms which use management and the share $s_{I T}$ of firms which use IT are given by

$$
s_{M}=\left(\frac{f(\widetilde{\xi}-1)}{\frac{w_{H}}{w_{L}} f_{M}}\right)^{\frac{k}{\varepsilon-1}} \text { and } s_{I T}=\left(\frac{f(\widetilde{\varphi}-\tilde{\xi})}{\frac{w_{H}}{w_{L}} f_{I T}}\right)^{\frac{k}{\varepsilon-1}} .
$$

when there are some firms with management which do not use IT, and otherwise, by

$$
s_{M}=s_{I T}=\left(\frac{(\tilde{\varphi}-1) f}{\frac{w_{H}}{w_{L}}\left(f_{M}+f_{I T}\right)}\right)^{\frac{k}{\varepsilon-1}} .
$$

These shares depend in an intuitive way on parameter values and on the skill premium. In particular, all else equal, a higher skill premium depresses management and IT adoption, as firms producing with these advanced technologies need to employ more high-skilled labour than firms producing with the basic technology. 
Free Entry. In equilibrium, the entry cost must be equal to the expected profits from firm creation. Using our previous results, this condition implies that

$$
\begin{aligned}
f_{E} w_{H}= & \int_{A^{*}}^{A_{M}^{*}}\left(\left(\frac{A}{w_{L}}\right)^{\varepsilon-1} B-f w_{L}\right) d G(A) \\
& +\int_{A_{M}^{*}}^{A_{I T}^{*}}\left(\tilde{\xi}\left(\frac{A}{w_{L}}\right)^{\varepsilon-1} B-f w_{L}-f_{M} w_{H}\right) d G(A) \\
& +\int_{A_{I T}^{*}}^{+\infty}\left(\tilde{\varphi}\left(\frac{A}{w_{L}}\right)^{\varepsilon-1} B-f w_{L}-\left(f_{M}+f_{I T}\right) w_{H}\right) d G(A) .
\end{aligned}
$$

Combining this equation with the definition of the productivity cut-offs and using the properties of the Pareto distribution, we get

$$
A^{*}=\left(\frac{(\varepsilon-1)\left(f+\frac{w_{H}}{w_{L}}\left(s_{M} f_{M}+s_{I T} f_{I T}\right)\right)}{(k-(\varepsilon-1)) \frac{w_{H}}{w_{L}} f_{E}}\right)^{\frac{1}{k}} .
$$

Equation (15) holds both when some firms with management do not use IT (then, $s_{M}$ and $s_{I T}$ are given by Equation (12)) and when all firms with management also use IT (then, $s_{M}$ and $s_{I T}$ are given by Equation (13p). It defines the exit cut-off as a function of parameter values and of the skill premium. To determine the latter, we need to consider the labour market clearing conditions.

Labour Market Clearing and Wages. High-skilled labour demand can be determined by aggregating over firms' demands for managerial labour and the fixed costs of entry, management and IT. Likewise, low-skilled labour demand is the sum of the aggregate demands for production labour and for the fixed cost of production. We derive both demand functions in Online Appendix $B$ and show that they define the relative demand for high-skilled labour as a decreasing function of the skill premium, given by

$$
\begin{aligned}
& \frac{H}{L}= \\
& \frac{\frac{k(\varepsilon-1) f}{\eta+\frac{w_{H}}{w_{L}}}\left(\widetilde{\xi}_{s_{M}^{1-\frac{\varepsilon-1}{k}}}^{1}+(\tilde{\varphi}-\widetilde{\xi}) s_{I T}^{1-\frac{\varepsilon-1}{k}}\right)+\left((\varepsilon-1) \frac{w_{L}}{w_{H}} f+k\left(s_{M} f_{M}+s_{I T} f_{I T}\right)\right)}{(k-(\varepsilon-1)) f+k(\varepsilon-1) f\left(1+\left(\frac{\widetilde{\xi}}{1+\frac{w_{H}}{\eta w_{L}}}-1\right) s_{M}^{1-\frac{\varepsilon-1}{k}}+\left(\frac{\widetilde{\varphi}-\tilde{\xi}}{1+\frac{w_{H}}{\eta w_{L}}}\right) s_{I T}^{1-\frac{\varepsilon-1}{k}}\right)} .
\end{aligned}
$$

By equating the relative demand of high-skilled labour with the relative supply, given by Equation (6), we obtain a non-linear equation for the skill premium, which can be solved numerically. 
Given the skill premium, it is easy to solve for the other endogenous variables. Equation (5) pins down the masses of high and low-skilled labour, Equations (12) or (13) the shares of firms using management and IT, and Equation (15) the value of the exit cut-off. Furthermore, note that free entry implies that all aggregate profits are paid as wages to workers. Thus, the national income identity implies $Y=w_{L} L+w_{H} H$. Combining this with the definition of the auxiliary variable $B$ and the exit cut-off defined by Equation (9), we get

$$
w_{L}=\frac{\varepsilon-1}{\varepsilon} A^{*}\left(\frac{L+\frac{w_{H}}{w_{L}} H}{\varepsilon f}\right)^{\frac{1}{\varepsilon-1}},
$$

which pins down $w_{L}$. From this, we can then directly deduce $w_{H}$ and output $Y$. Finally, Online Appendix $B$ shows how we can use the labour market clearing conditions to also determine the mass of producing firms $M$.

Having completely characterized the equilibrium in the North, we can now turn to the South. Our analysis will be largely symmetrical, except for the fact that we now need to consider migration.

\subsubsection{Equilibrium Conditions for Southern Countries.}

Worker Decisions. The income of a Southern worker of type $j$ who decides to stay at home is given by $w_{L}^{S}$ if she supplies low-skilled labour and by $j^{v_{1}} w_{H}^{S}$ if she supplies high-skilled labour. A high-skilled worker which decides to emigrate to the North earns instead $j^{v_{1}+v_{2}} w_{H}^{N}$. Recall that because the South is arbitrarily small, Northern wages do not depend on the Southern equilibrium and can be considered as parameters in this section.

As Northern wages are higher than Southern ones, some workers are better off emigrating. As a consequence, Southern workers sort into three groups: workers with types below $j^{S *}$ supply low-skilled labour at home, workers between $j{ }^{S *}$ and $j_{E}{ }_{E}^{*}$ supply high-skilled labour at home, and workers with types larger than $j_{E}^{S *}$ emigrate and supply high-skilled labour in the North. Cut-offs are given by

$$
j^{S *}=\left(\frac{w_{L}^{S}}{w_{H}^{S}}\right)^{\frac{1}{\nu_{1}}} \text { and } j_{E}^{S *}=\left(\frac{w_{H}^{S}}{w_{H}^{N}}\right)^{\frac{1}{\nu_{2}}} .
$$

Accordingly, the supply of high-skilled and low-skilled labour in a Southern country is given by

$L^{S}=\left(\frac{w_{L}^{S}}{w_{H}^{S}}\right)^{\frac{1}{\nu_{1}}}$ and $H^{S}=\int_{j S^{*}}^{j_{E}^{S *}} j^{\nu_{1}} d j=\frac{1}{1+v_{1}}\left(\left(\frac{w_{H}^{S}}{w_{H}^{N}}\right)^{\frac{1+\nu_{1}}{\nu_{2}}}-\left(\frac{w_{L}^{S}}{w_{H}^{S}}\right)^{\frac{1+\nu_{1}}{\nu_{1}}}\right)$. 
Thus, the relative supply of high-skilled labour is

$$
\frac{H^{S}}{L^{S}}=\frac{1}{1+v_{1}}\left(\frac{w_{H}^{S}}{w_{L}^{S}}\right)^{\frac{1}{v_{1}}}\left(\left(\frac{w_{H}^{S}}{w_{H}^{N}}\right)^{\frac{1+v_{1}}{\nu_{2}}}-\left(\frac{w_{L}^{S}}{w_{H}^{S}}\right)^{\frac{1+v_{1}}{v_{1}}}\right) .
$$

Note that the relative supply of high-skilled labour now does not only depend on the skill premium, but also on the ratio of Southern to Northern high-skilled wages. When this ratio decreases, emigration increases and the Southern relative supply of high-skilled labour shifts downwards.

Firm Decisions and Equilibrium. Firm decisions in the South can be determined exactly as in the North. In particular, Equation (16) still defines the relative demand for high-skilled labour. However, the condition that relative supply and demand of high-skilled labour are equal is no longer sufficient to pin down the skill premium, as the relative supply now also depends on the ratio of Southern to Northern high-skilled wages. Therefore, we need an additional equilibrium condition. This condition is given by equation (17), which also holds for Southern countries. Together with the relative labour market clearing condition, it defines a system of two equations in two unknowns (the Southern wages $w_{L}^{S}$ and $w_{H}^{S}$ ) that can be solved numerically.

Knowing Southern wages, we can deduce the equilibrium values of the other endogenous variables: domestic supply of high and low-skilled labour is given by Equation 19, national income is still given by $Y^{S}=w_{L}^{S} L^{S}+w_{H}^{S} H^{S}$, and the mass of firms $M^{S}$ can be determined in the same way as for the Northern countries.

This concludes the characterization of our model's solution. In the next section, we explain how we use it to analyse the IT Revolution, and how the latter generates divergence between the North and the South. This illustrates the channels at work and paves the way for a quantitative analysis of divergence in Section 4.

\subsection{Results: IT, Management Efficiency and Divergence}

3.3.1. The North and the South before and after the IT Revolution. To analyse the impact of the IT Revolution, we compare our model's equilibrium with $\varphi=0$, which represents the situation "before" the IT Revolution, to its equilibrium with $\varphi>0$, which represents the situation "after" the IT Revolution. Figure 4 provides a graphical illustration of our main results, by plotting the equilibrium values of several key variables for different values of $\varphi{ }^{19}$ Even though our model is static, one could interpret the figure as showing a succession of steady states over time as the IT Revolution progresses and IT becomes more and more productive. The parameter values used for this figure are the same as in the baseline calibration of our quantitative analysis (see Section 4).

19. As our model does not admit an analytical solution, we cannot formally prove all numerical results. In Online Appendix B we however provide some analytical proofs for a simplified version of our model, without migration and worker heterogeneity. 
Even before the IT Revolution, there are several differences between the North and the South. As management is less efficient in the South, management adoption is lower as well, as shown in Panel 2. Furthermore, the Southern firms which adopt management do not increase their productivity as much as their Northern counterparts. This reduces the competitive pressure on low-productivity firms and thus the cutoff level of productivity needed to stay in the market (see Panel 3). As a result, Southern countries have on average smaller firms than Northern ones (see Panel 4), lower aggregate productivity and lower national income (see Panel 1). Moreover, lower management adoption rates depress the demand for high-skilled labour, lowering both the skill premium and the high-skilled share of the workforce, as shown in Panel 5. Finally, as Northern wages are higher than Southern ones, some Southern high-skilled workers emigrate. This shifts the Southern high-skilled labour supply downwards, which all else equal increases the skill premium (reflecting the fact that the marginal high-skilled worker now faces a higher education cost).

Thus, assuming only one simple difference between the North and the South, our model can reproduce many stylized facts: compared with other OECD members, Southern Europe has smaller firms, less management, lower productivity, less highskilled workers and more high-skilled emigration.

Figure 4 also shows that the qualitative effects of the IT Revolution are the same in both regions. More productive IT obviously raises IT adoption (see Panel 2) and national income (see Panel 1). It also enhances selection: as high-productivity firms adopt IT and increase their market share, some low-productivity firms exit the market and average firm size increases (see Panels 3 and 4). Furthermore, the IT Revolution raises the demand for high-skilled labour (which is needed for IT adoption costs) and therefore jointly raises the skill premium and the high-skilled share of the workforce 20 This analysis shows that the IT Revolution raises incomes both in the North and in the South. However, as Figure 4 already indicates, it increases Northern incomes more than Southern ones. We turn to this point in the next section.

\subsubsection{Drivers of Divergence. Figure 5 plots output per worker in a Northern and} in a Southern country as a function of the state of IT technology $\varphi$. Both series are normalized to 1 in the equilibrium before the IT Revolution. Output per worker is our model's equivalent to aggregate productivity in the data, and from now on, we refer to it simply as productivity. The figure clearly shows that the IT Revolution increases productivity differences between the North and South, and that this effect is increasing in $\varphi$. This divergence arises through three channels.

20. Management adoption by firms which do not use IT is subject to opposing forces. On the one hand, higher skilled wages and lower market shares due to stronger competition from IT-adopting firms reduce the incentives of firms to use management without IT. On the other hand, higher selection lowers the mass of low-productivity firms producing with the basic technology, and therefore mechanically increases the share of producing firms which use management. Depending on which effect is stronger, an increase in $\varphi$ lowers or increases the share of firms with management. However, once $\varphi$ passes a certain threshold, further increases unambiguously raise management adoption, as it is a prerequisite for IT adoption. Furthermore, the IT Revolution always raises the fraction of workers employed by firms that use management. 

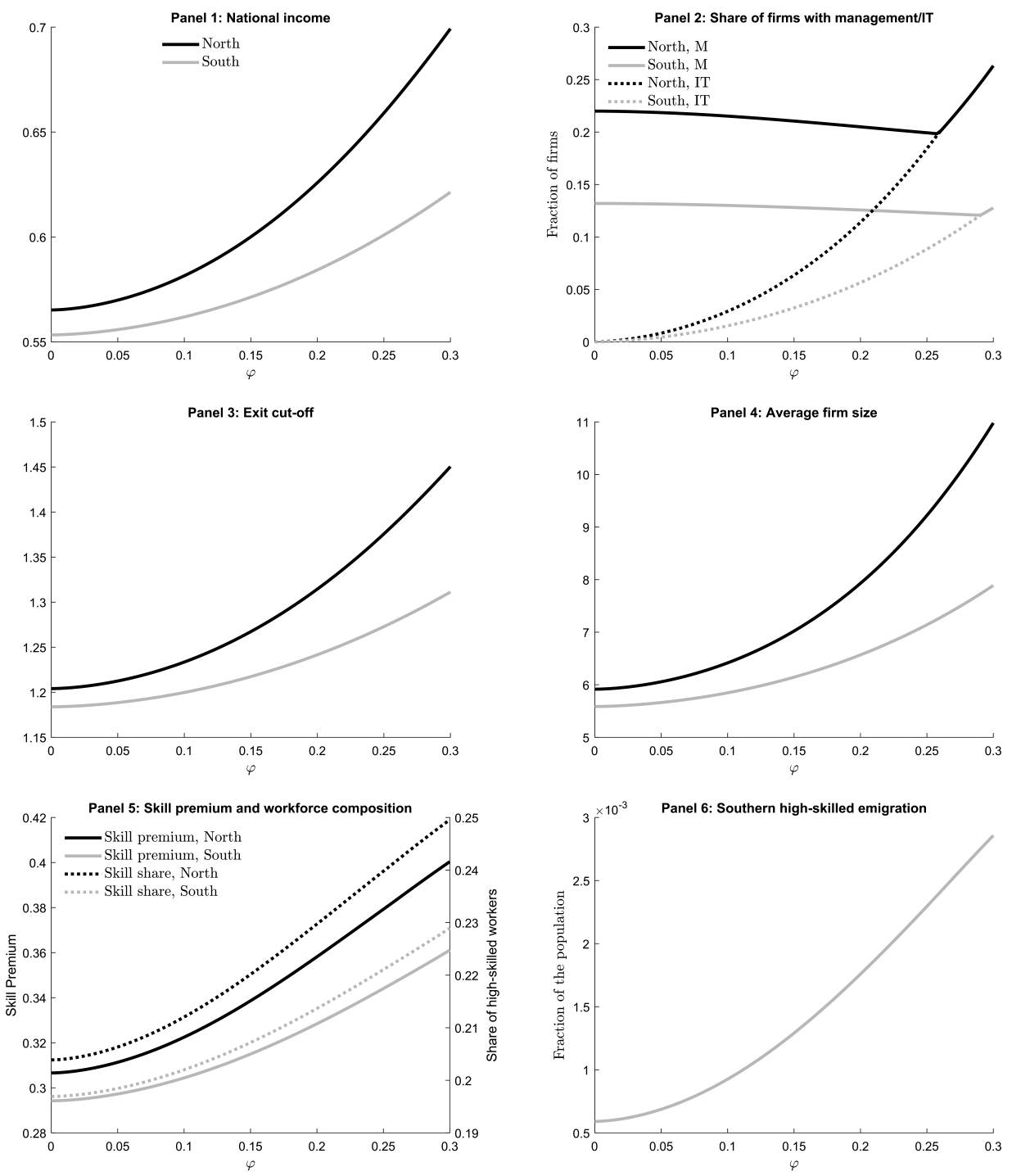

FIgure 4. The impact of the IT Revolution. The parameter values used to draw these figures correspond to the baseline calibration (see Section 4). The North corresponds to our calibration for Germany, the South to our calibration for Italy.

First, the management-IT complementarity means that Southern firms get a smaller productivity gain than Northern ones when adopting IT. Obviously, this directly implies that Southern aggregate productivity gains are also lower. This is compounded by the fact that Southern IT adoption rates are lower (consistent with the evidence shown in Table 1): all else equal, Southern firms have less incentives to adopt IT, and because of inefficient management, they are on average smaller and thus less willing to pay the fixed cost of IT adoption. When IT productivity becomes arbitrarily 


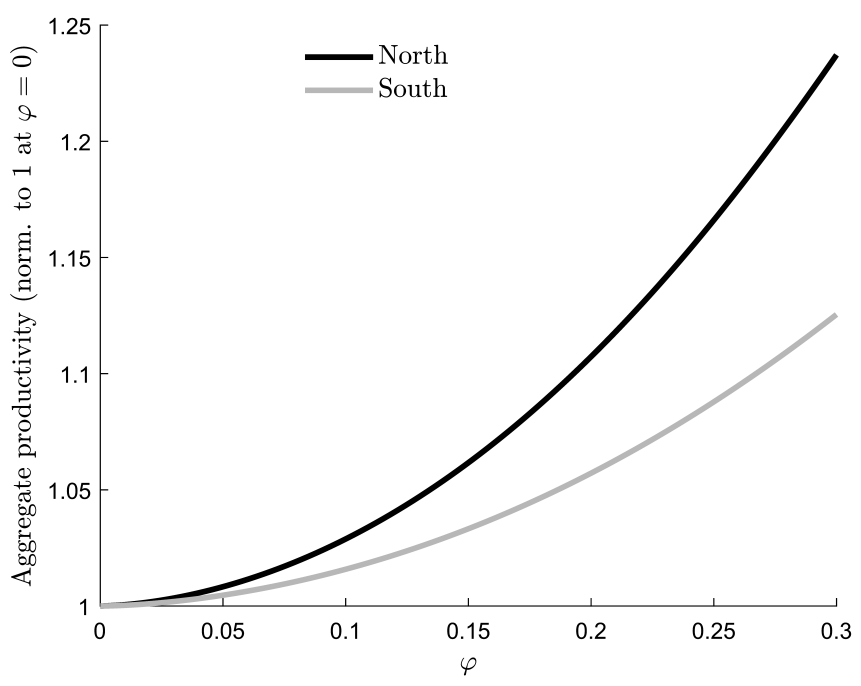

Figure 5. The IT Revolution and productivity divergence in the model. See Figure 4

high, all firms use IT and differences in adoption rates disappear. However, our log-supermodular specification of production technology implies that differences in productivity gains between Northern and Southern firms increase in IT productivity, so that divergence monotonically increases with the strength of the IT Revolution.

Second, the IT Revolution makes the South's management disadvantage more salient through a composition effect. Southern firms are as productive as Northern ones for the basic technology, but less productive for management. Thus, as the IT Revolution increases the employment share of firms using management, it fosters divergence. Note that this channel does not directly depend on the managementIT complementarity, but is essentially due to the size-biased nature of IT. Indeed, management is only adopted by large firms. Thus, any other new technology that is only adopted by large firms increases the employment share of firms with management and triggers divergence.

Third, the IT Revolution increases Northern wages more than Southern ones, and therefore endogenously increases Southern high-skilled emigration rates (see Panel 6 of Figure 4). This lowers Southern productivity, as it increases the education cost faced by the marginal high-skilled worker. It also, all else equal, increases the skill premium, and therefore further depresses IT adoption.

Note that technological change does not always leads to divergence between countries with different levels of management efficiency. For instance, in our model, Hicks-neutral technological change without fixed costs (modelled as an upward shift in the exogenous productivity distribution) would have an exactly symmetrical effect across all countries. The IT Revolution only leads to divergence because it is both management- and size-biased. 
Thus, our analysis suggests a simple narrative for Southern Europe's growth performance in recent economic history. In the decades before the 1990s, technological change was neither size- nor management-biased, and Southern Europe grew at least as fast as other OECD countries 21 In the middle of the 1990s, however, the nature of technological change changed. The new frontier technology, IT, had a strong complementarity with efficient management practices and therefore stimulated TFP growth in Southern Europe less than in other countries, made its management problems more salient, and incentivized more and more highly educated workers to emigrate. We now proceed to a quantitative analysis of these mechanisms.

\section{Quantitative Results}

In this section, we assess the importance of the IT Revolution for the divergence between three Southern European countries (Italy, Spain and Portugal) and Germany, the largest economy in Northern Europe, between 1995 and 2008 ${ }^{22}$ To do so, we assume that Germany is representative for the North in our model, and consider successively each of the three Southern European countries as representative for the South ${ }^{23}$ We then calibrate the model using micro- and macro-level evidence on the productivity effects of management and IT adoption, and a series of moments for Germany in 2008. Throughout, the only difference between the parametrization for Germany and for the three Southern European countries is the value of the management efficiency parameter $\xi$. As before, we assess the IT Revolution by comparing our model's equilibrium without IT (where $\varphi=0$ ) to its equilibrium with IT (where $\varphi=\varphi_{I T}$, which is a positive number to be calibrated).

\subsection{Calibration}

4.1.1. Externally Calibrated Parameters. The firm-level productivity gains from management and IT adoption depend on six parameters: the management efficiency

21. In fact, Southern European TFP growth was generally higher than the OECD average before the 1990s. One interpretation of this fact that is consistent with our narrative is that during that period, the type of technological progress most relevant for Southern Europe was biased towards basic technologies and unskilled labour. Indeed, during its catch-up phase, Southern Europe experienced a massive shift from agriculture to manufacturing and imported technologies that were already widespread in frontier economies and that did not rely heavily on efficient management.

22. We stop in 2008, as the subsequent financial crisis may have amplified divergence for reasons not captured in our model. However, we show below that a calibration for the whole period 1995-2015 leads to very similar results.

23. Alternatively, we could allow for heterogeneity among Southern countries in our model, and consider all three countries jointly. This would not change results, as Southern countries do not interact (Southern emigrants move to the North, not to other Southern countries). Considering Germany as representative for the North is a conservative choice. As shown in Figure 3 it had lower productivity growth than the United States and the United Kingdom, and thus also presumably lower wage growth, reducing the pull factor of its wage increases for Southern emigrants. 
and IT parameters $\xi$ and $\varphi_{I T}$, and the elasticities which determine how they map into productivity $\left(\alpha_{0}\right.$ to $\left.\alpha_{3}\right)$. With one important exception, we set all these parameter values externally, relying on micro-level evidence.

In order to calibrate management efficiency $\xi$, we rely on the WMS management scores described in Section 2, and set $\xi$ equal to the average standardized management score for every country considered: 0.467 for Germany, 0.110 for Italy, -0.124 for Portugal and -0.232 for Spain. Calibrating the contribution of IT is trickier. The parameter $\varphi_{I T}$ captures the total productivity impact of the IT Revolution. As we discussed in Section 2. IT consists of a large number of heterogeneous technologies. Therefore, it would be hard to rely on microeconomic evidence for one specific technology (such as computers, ERP, SCM or the internet) to pin down $\varphi_{I T}$. Instead, we will calibrate this parameter internally, by targeting an aggregate growth rate which is consistent with the best estimates for the contribution of IT to aggregate productivity growth in the frontier economies between 1995 and 2008.

In order to calibrate the elasticity parameters $\alpha_{0}-\alpha_{3}$, we note that in our model output per production worker of a management-adopting firm $i$ is given by

$$
\ln \left(\frac{y_{i}}{l_{i}}\right)=\alpha_{0}+\alpha_{1} \xi+\mathbb{1}_{I T_{, i}}\left(\alpha_{2} \varphi_{I T}+\alpha_{3} \xi \varphi_{I T}\right)+\ln \left(A_{i}\right),
$$

where $\mathbb{1}_{I T_{, i}}$ is an indicator function that equals 1 if firm $i$ adopts IT, and 0 if it does not. In order to take Equation (21) to the data, we make three additional assumptions. First, while in our model we assumed for simplicity that all firms from a given country have the same management efficiency, we allow management efficiency to be firm-specific in the data, and measure it, as above, with the firm's standardized WMS score. Second, while IT adoption is a binary decision in our model, we allow it to be continuous in the data, and proxy firm $i$ 's degree of IT adoption by the variables introduced in Section 2 that is, by the fraction of a firm's plants using a certain software. Third, in the absence of firm-level prices, we make the widely used assumption that output per worker can be approximated with sales per worker. Thus, our measurement equation becomes

$$
\ln \left(\frac{\text { Sales }_{i}}{l_{i}}\right)=\alpha_{0}+\alpha_{1} W M S_{i}+\alpha_{2} \varphi_{I T} I T_{i}+\alpha_{3} \varphi_{I T} W M S_{i} \cdot I T_{i}+\ln \left(A_{i}\right) .
$$

Equation 22 corresponds to our specification in Table 2 of the empirical section. Throughout, we focus on Column [1] of the table, which contains the results for the most general measure of IT adoption 24 These results suggest $\alpha_{1} \approx 0.05$. That is, abstracting from IT, a unit increase in the standardized management score increases firm productivity by around 5\%. This estimate is in the range of the empirical evidence summarized in Bloom et al. (2016), who, based on experimental and cross-sectional evidence, conclude that a unit increase in the standardized management score increases

24. Note that the WMS only targets medium-size firms (between 50 and 5000 employees) that are expected to have a formal management structure. This is consistent with the assumption that we estimate equation 22, on a sample of management-adopting firms. 
firm productivity by around $10 \%$. Given that this estimate is based on a large body of evidence, we use $\alpha_{1}=0.1$ in our baseline calibration, but we show in Section 4.3 that results are similar when setting $\alpha_{1}=0.05$.

Furthermore, our estimates suggest $\alpha_{2} \varphi_{I T} \approx 0.085$ and $\alpha_{3} \varphi_{I T} \approx 0.091$. As the scale of $\varphi_{I T}$ is indeterminate in our model ${ }^{25}$ we normalize $\alpha_{2}=1$ and then set $\alpha_{3}=$ $0.091 / 0.085 \approx 1.071$. This estimate is remarkably similar to the one of Bloom et al. (2012), who estimate a close equivalent of Equation (22) using hardware adoption (computers per worker) as a measure of IT and find $\alpha_{3} \approx 1.014{ }^{26}$ Thus, the degree of management-IT complementarity implied by our calibration of $\alpha_{3}$ seems to apply to a broad range of IT technologies, which is reassuring.

Finally, we need to calibrate the parameter $\alpha_{0}$. For this, we cannot rely on the estimates in Table 2, as the constant in our regression confounds $\alpha_{0}$ and common components in firm productivity. Instead, we note that in our model, a firm which adopts management increases its productivity by $\alpha_{0}+\alpha_{1} \xi \log$ points. Thus, if we had an estimate for the increase in productivity induced by management adoption, we could pin down $\alpha_{0}$. To get this number, we rely on a dataset constructed by Guiso et al. (2015), who ran a close equivalent of the WMS on a sample of small Italian firms without formal management structures (see Online Appendix A for a full description of the dataset). The average management score of these firms is -1.110. Assuming that management adoption brings them to the average management score of management-adopting firms in Italy (0.110), and using the Bloom et al. (2016) elasticity of productivity to better management, management adoption increases their productivity by $(0.11-(-1.11)) \cdot 0.1=0.122 \log$ points, implying $\alpha_{0}=0.111$. We will consider extensive robustness checks on all of these parameter values in Section 4.3 .

TABLE 4. Externally calibrated parameters.

\begin{tabular}{cll|cll}
\hline Parameter & Value & Description & Parameter & Value & Description \\
\hline$\xi^{D E U}$ & 0.467 & Management efficiency, Germany & $\alpha_{1}$ & 0.1 & Elasticity of prod. w.r. to $\xi$ \\
$\xi^{I T A}$ & 0.110 & Management efficiency, Italy & $\alpha_{2}$ & 1 & Elasticity of prod. w.r. to $\varphi$ \\
$\xi^{P R T}$ & -0.124 & Management efficiency, Portugal & $\alpha_{3}$ & 1.071 & Elasticity of prod. w.r. to $\xi \varphi$ \\
$\xi^{E S P}$ & -0.232 & Management efficiency, Spain & $\varepsilon$ & 3 & Elasticity of substitution \\
$\alpha_{0}$ & 0.111 & Direct effect of mgmt & $k$ & 3.3 & Pareto shape parameter \\
\hline
\end{tabular}

25. Indeed, we can always rewrite the productivity increase due to IT adoption as $\exp \left(\left(\alpha_{2} \varphi_{I T}\right)+\alpha_{3} / \alpha_{2} \xi\left(\alpha_{2} \varphi_{I T}\right)\right)$.

26. These results are stated in Column 3 of Table 6 (P.195) of Bloom et al. (2012). The coefficient on computers per worker is 0.143 , while the coefficient on the interaction of computers per worker and management score is 0.145 . 
We calibrate two more parameters externally. Following common practice in the literature, we set the elasticity of substitution between intermediates to 3 (Hsieh and Klenow 2009, Jones 2011). The tail of the firm size distribution in our model is Pareto with shape parameter $k /(\varepsilon-1)$. To match the shape of size distributions in the data, we set $k$ such that $k /(\varepsilon-1)=1.65$, following Arkolakis (2010). His estimate, which uses French data, is close to the median value used in the literature on quantitative Melitz models (for instance, Chaney (2008) uses 2, while Melitz and Redding (2015) use 1.42). We consider robustness tests for both the elasticity of substitution and the shape parameter of the size distribution in Section 4.3

4.1.2. Internally Calibrated Parameters. There are eight more parameters to calibrate: the state of IT technology $\varphi_{I T}$, the fixed costs of entry $f_{E}$, of production $f$, of management adoption $f_{M}$, of IT adoption $f_{I T}$, the span of control of managers $\eta$ and the parameters determining the costs of skill acquisition $v_{1}$ and migration $v_{2}$. We set these parameter values by choosing the parameter vector $\boldsymbol{\theta}=\left(\varphi_{I T}, f_{E}, f, f_{M}, f_{I T}, \eta, v_{1}, v_{2}\right)$ that solves

$$
\min _{\boldsymbol{\theta}} \sum_{s=1}^{8}\left(\frac{\text { Moment }_{s}(\text { Data })-\text { Moment }_{s}(\boldsymbol{\theta}, \text { Model })}{\text { Moment }_{s}(\text { Data })}\right)^{2}
$$

All moments refer to the model's equilibrium for Germany after the IT Revolution. Most importantly, we target German productivity growth induced by the IT Revolution. In our model, this corresponds to the increase in Germany's aggregate productivity between the equilibrium without IT and the equilibrium with IT. To pin down this growth rate, we rely on growth accounting evidence. For the United States, Byrne et al. (2013) find that IT accounted for 57\% of all growth in real output per worker (net of non-IT capital deepening) in the nonfarm business sector between 1995 and 2008. At the same time, the OECD data discussed in the introduction indicates an overall US productivity (real output per hour worked, net of non-IT capital deepening) growth of $25.2 \%$. Thus, assuming that the decomposition of Byrne et al. for the nonfarm business sector also applies to the overall economy, IT accounts for a $13.6 \%$ increase in US productivity between 1995 and 2008 ${ }^{27}$ To the best of our knowledge, there are no comparable studies for Germany. We therefore use our model to discipline the German growth rate, by assuming that if Germany's management score were equal to the one of the US ${ }^{28}$ German productivity would also have grown by $13.6 \%$. We consider robustness checks for this target in Section 4.3 .

27. According to Table 1 in Byrne et al. (2013), real GDP per worker in the US nonfarm business sector grew by $33.8 \log$ points between 1995 and 2008. Netting out the contribution of non-IT capital $(5.5 \log$ points), a productivity growth rate of $28.3 \log$ points remains. As the total contribution of IT to growth in real GDP per worker during these years was $16.1 \log$ points, it follows that IT accounted for $57 \%(16.1 / 28.3)$ of all productivity growth. Assuming that the same percentage holds for the overall economy, and noting that the OECD data discussed in the introduction implies that US productivity has increased by $22.5 \mathrm{log}$ points between 1995 and 2008 yields an overall IT contribution of $12.7 \log$ points $(0.57 \cdot 22.5)$, or $13.6 \%$. 28. The average management score of US firms is $\xi^{U S A}=0.612$. 
Second, we target the share of German employment in IT-using firms. As noted before, IT refers to a wide array of technologies. Thus, there is no single adoption rate: while nearly all firms have access to the internet, only a subset of firms use ERP or SCM software. For our main IT adoption measures discussed in Section 2. adopting firms represent approximately 40\% (for CRM and SCM), 65\% (for ERP) or more than $95 \%$ (for the internet) of total employment in Germany in $2014{ }^{29}$ Thus, we target an employment share of $50 \%$ for 2008 , but perform extensive robustness checks around this value. Together with the German growth rate, this moment disciplines the strength of the IT Revolution in the model, that is, the parameters $\varphi_{I T}$ and $f_{I T}$.

Third, we target the share of German employment in management-using firms. As in the previous section, we identify firms which use management with firms having at least 50 employees. Using Eurostat's structural business statistics (SBS), we find that the employment share of firms with more than 50 employees was $57.9 \%$ in 2012 , the first year in which a decomposition of employment by size classes is available. This moment disciplines the fixed cost of management adoption $f_{M}$.

Fourth, we target the average number of employees of German firms and firms' exit rate, using again the SBS. These show that in 2008, the average German firm had 8.0 employees. In our model, all exit occurs endogenously immediately after entry. Many studies (e.g., Bartelsman et al. (2005) for a set of OECD countries and Fackler et al. (2013) for Germany), show that exit hazard rates of entering firms stabilize approximately five years after entry. The Eurostat SBS show that in 2009 (the first year in which this data is available), $40.2 \%$ of all German firms which entered in 2004 were still active, so we target an endogenous exit rate of $59.8 \%$. Average employment and the exit rate jointly determine the fixed costs $f_{E}$ and $f$.

29. See Online Appendix $\mathrm{A}$ for further details on this and on the following data sources. 
TABLE 5. Targeted moments.

\begin{tabular}{llcc}
\hline Moment & Country & Data & Model \\
\hline IT-induced productivity growth & United States & $13.6 \%$ & $13.6 \%$ \\
IT-induced productivity growth & Germany & n.a. & $11.1 \%$ \\
Employment in firms with IT & Germany & $50.0 \%$ & $50.0 \%$ \\
Employment in firms with management & Germany & $57.9 \%$ & $57.7 \%$ \\
Average firm size (employees) & Germany & 8.0 & 8.0 \\
Exit rate & Germany & $59.8 \%$ & $59.8 \%$ \\
Percentage of high-skilled workers & Germany & $22.2 \%$ & $23.0 \%$ \\
Skill premium & Germany & $35.8 \%$ & $35.9 \%$ \\
Emigration (perc. of high-skilled pop.) & South & $1.26 \%$ & $1.26 \%$ \\
\hline
\end{tabular}

Note: Data sources for all moments are described in the main text, and in greater detail in Online Appendix A.1

Fifth, we target the share of high-skilled workers in the German workforce and the German skill premium, using the EU SILC database. Throughout, we define highskilled workers in the data as workers with tertiary education. The data show that in $2015,22.2 \%$ of the German population between 18 and 64 years had tertiary education, and that the average net annual income of these people was $35.8 \%$ higher than that of the rest of the population. The skill premium and the share of high-skilled workers jointly discipline the span of control of managers $\eta$ and the education cost parameter $v_{1}$.

Finally, German moments can of course not identify the migration cost parameter $v_{2}$, as there is no German emigration in our model. Thus, we discipline this last parameter using the DIOC database introduced in Section 2.3 The data show that in 2010/2011, the net stock of high-skilled Southern emigrants in the North amounted to $1.26 \%$ of their domestic high-skilled population, and we target this number 30

We solve the minimization problem defined by Equation (23) with a Differential Evolution algorithm. Table 5 shows that our model matches the targeted moments very closely (which is not surprising, given that the calibration is exactly identified). The model implies a German productivity growth of $11.1 \%$, around $82 \%$ of the US value. Table 6 shows the implied parameter values.

30. Precisely, to calibrate $\nu_{2}$, we consider a hypothetical Southern country whose management score is the simple average of the scores of Italy, Portugal and Spain. Results do not change if we use a populationweighted average. 
TABLE 6. Internally calibrated parameters.

\begin{tabular}{|c|c|c|c|c|c|}
\hline Parameter & Value & Description & Parameter & Value & Description \\
\hline$f_{E}$ & 0.557 & Entry cost & $\varphi_{I T}$ & 0.203 & State of IT technology \\
\hline$f$ & 0.737 & Fixed cost of production & $\eta$ & 100 & Managers' span of control \\
\hline$f_{M}$ & 0.474 & Management adoption cost & $v_{1}$ & 1.173 & Education cost parameter \\
\hline$f_{I T}$ & 2.220 & IT adoption cost & $v_{2}$ & 47.21 & Emigration cost parameter \\
\hline
\end{tabular}

The fixed costs imply reasonable magnitudes for adoption costs: IT adoption and management costs jointly represent approximately $5.2 \%$ of German national income. The average high-skilled worker uses up around $13.3 \%$ of her labour endowment in education, and the average manager can supervise around 87 production workers ${ }^{31}$

4.1.3. Model Fit. To examine our model's fit, Table 7 compares its moments generated for Southern European countries after the IT Revolution to their (nontargeted) data equivalents in 2008, or in the closest year with available data. Even though our calibration used almost no information on Southern Europe, it roughly matches the Southern European shares of firms with management and exit rates. Average firm size and the share of high-skilled workers in the workforce are lower in Southern Europe than in Germany, even though the model somewhat overpredicts their level with respect to the data ${ }^{32}$ Finally, it turns out that in the data, skill premia are higher in Southern Europe than in Germany. This finding may be due to taxes. For our calibration, we have used data on net wages, as these are most relevant for workers making occupational choices. However, when looking at gross wages, which are more directly subject to market forces, it turns out that the skill premium in Italy is substantially lower than in Germany, and the one in Spain is somewhat lower 33

31. The average high-skilled worker supplies 0.867 units of labour, and every unit can supervise 100 production workers.

32. Spain is an exception in this regard, with a very high share of the population having tertiary education.

33. Data for gross wages from the OECD "Education and Training" database gives a gross skill premium of $59.4 \%$ for Germany (in 2014), $50.4 \%$ for Italy and $58.8 \%$ for Spain (in 2013). 
TABLE 7. Non-targeted moments (Southern Europe, after the IT Revolution.)

\begin{tabular}{lcccccc}
\hline & \multicolumn{2}{c}{ Italy } & \multicolumn{2}{c}{ Portugal } & \multicolumn{2}{c}{ Spain } \\
\hline & Data & Model & Data & Model & Data & Model \\
\hline Emp. in firms with management & $33 \%$ & $46 \%$ & $37 \%$ & $37 \%$ & $40 \%$ & $32 \%$ \\
Average firm size (employees) & 4.1 & 6.6 & 3.7 & 6.0 & 4.3 & 5.8 \\
Exit rate & $50 \%$ & $51 \%$ & $65 \%$ & $46 \%$ & $51 \%$ & $44 \%$ \\
Share of high-skilled workers & $14 \%$ & $21 \%$ & $13 \%$ & $20 \%$ & $29 \%$ & $20 \%$ \\
Skill premium & $52 \%$ & $33 \%$ & $110 \%$ & $31 \%$ & $50 \%$ & $30 \%$ \\
\hline
\end{tabular}

Note: Data sources and definitions are the same as for Germany. See details in Online Appendix A

Overall, this evidence suggests that management efficiency (the only difference between Southern Europe and Germany in our model) can explain a substantial part of several cross-country differences in the productive structure, even though it can of course not account for all the differences. We are now ready to consider our model's predictions for divergence.

\subsection{Quantitative Implications}

Table 8 contains our model's main quantitative predictions. Column [1] shows some summary statistics for the equilibrium before the IT Revolution (where $\varphi=0$ ). Germany's higher management efficiency already implies a $2.0 \%$ productivity gap with respect to Italy, a 3.1\% gap with respect to Portugal, and a 3.6\% gap with respect to Spain. The IT Revolution amplifies these differences, as its productivity impact is lower in Southern Europe. This can be seen in Column [2], showing the equilibrium after the IT Revolution (where $\varphi=\varphi_{I T}$ ): with respect to the equilibrium before the IT Revolution, aggregate productivity increases by $11.1 \%$ in Germany, but only by $5.9 \%$ in Italy, 3.4\% in Portugal and 2.5\% in Spain. Differences between Southern European countries reflect their management scores: Italy fares best because it has the highest score in Southern Europe, and Spain worst because it has the lowest one. Furthermore, divergence is stronger for high-skilled wages, as the skill premium rises more strongly in Germany than in Southern Europe.

How much of the actually observed divergence between Southern Europe and Germany can be explained by the IT Revolution? To answer this question, we confront the divergence generated by our model to the one observed in the data. According to the OECD data discussed in the introduction (see Figure 1), the difference in aggregate productivity growth rates with respect to Germany was 14.9 percentage points for Italy, 18.4 percentage points for Spain, and 9.4 percentage points for Portugal. In our model, the corresponding numbers are 5.2, 7.7 and 8.6 percentage points. Thus, over the period 1995-2008, our model accounts for 35\% (5.2/14.9) of Italy's , 47\% 
TABLE 8. Quantitative results for the baseline calibration.

\begin{tabular}{|c|c|c|c|c|c|c|c|c|}
\hline & & $\begin{array}{r}\text { [ } \\
\text { With }\end{array}$ & $\begin{array}{l}\text { 1] } \\
\text { out IT }\end{array}$ & & \multicolumn{4}{|c|}{$\begin{array}{c}{[2]} \\
\text { With IT }\end{array}$} \\
\hline & DEU & ITA & PRT & ESP & DEU & ITA & PRT & ESP \\
\hline Productivity rel. to Germany & 1 & 0.980 & 0.969 & 0.964 & 1 & 0.934 & 0.902 & 0.890 \\
\hline Productivity growth & & & & & $11.1 \%$ & $5.9 \%$ & $3.4 \%$ & $2.5 \%$ \\
\hline Share of actual divergence & & & & & & $35 \%$ & $81 \%$ & $47 \%$ \\
\hline Low-skilled wage rel. to Germany & 1 & 0.982 & 0.972 & 0.968 & 1 & 0.940 & 0.911 & 0.900 \\
\hline High-skilled wage rel. to Germany & 1 & 0.972 & 0.958 & 0.952 & 1 & 0.919 & 0.878 & 0.863 \\
\hline Emp. in firms with management & $49 \%$ & $39 \%$ & $32 \%$ & $28 \%$ & $58 \%$ & $46 \%$ & $37 \%$ & $32 \%$ \\
\hline Emp. in firms with IT & $0 \%$ & $0 \%$ & $0 \%$ & $0 \%$ & $50 \%$ & $36 \%$ & $27 \%$ & $23 \%$ \\
\hline Skill premium & $31 \%$ & $29 \%$ & $29 \%$ & $28 \%$ & $36 \%$ & $33 \%$ & $31 \%$ & $30 \%$ \\
\hline Share of high-skilled workers & $20 \%$ & $20 \%$ & $19 \%$ & $19 \%$ & $23 \%$ & $21 \%$ & $20 \%$ & $20 \%$ \\
\hline Emigrants (\% of high-skilled) & $0 \%$ & $0.3 \%$ & $0.5 \%$ & $0.6 \%$ & $0 \%$ & $0.8 \%$ & $1.4 \%$ & $1.6 \%$ \\
\hline Emigrants ( $\%$ of total population) & $0 \%$ & $0.06 \%$ & $0.09 \%$ & $0.10 \%$ & $0 \%$ & $0.18 \%$ & $0.27 \%$ & $0.31 \%$ \\
\hline
\end{tabular}

Note: The figures shown correspond to the equilibrium of our model without IT $(\varphi=0)$ and with IT $\left(\varphi=\varphi_{I T}\right)$. All parameters are equal to their baseline calibration values, and productivity is measured as output per worker.

(8.6/18.4) of Spain's and 81\% (7.7/9.4) of Portugal's divergence with respect to Germany.

As discussed in Section 3, divergence is due to three channels: the direct effect of lower IT adoption and lower productivity gains from adopted IT, the increase in the employment share of firms with management, and high-skilled emigration. We can use the model to assess the relative strength of these channels. To do so, we start by shutting down the first channel, setting $\alpha_{3}=0$ and recalibrating the model to match the targets described in the previous section ${ }^{34}$ Now, Southern European and German firms experience the exact same productivity increase when adopting IT. However, the IT Revolution still triggers divergence, because it increases the employment share of firms with management and stimulates emigration. In this alternative calibration, differences in productivity growth are substantially lower, amounting to 0.6 percentage points for Italy, 1.1 percentage points for Portugal and 1.4 percentage points for Spain. Thus, lower productivity gains and lower IT adoption account for the largest part of divergence, while the remainder is due to composition changes and emigration. Among these latter channels, composition changes dominate. Indeed, emigration has only a small effect: when we set the migration cost parameter $v_{2}$ to $+\infty$ in our baseline

34. We need to recalibrate the model because otherwise, the implied growth rate for Germany would be much lower, and our results for the alternative parametrization would not be comparable to the baseline. 
calibration, thus shutting down emigration, productivity growth only increases by 0.12 percentage points in Italy, 0.17 percentage points in Portugal, and 0.19 percentage points in Spain 35

Thus, the most important driver of divergence is the fact that Southern European firms adopt less IT and benefit less from the IT they adopted. The increase in the aggregate importance of management triggered by the IT Revolution also makes a non-negligible contribution, while emigration of high-skilled workers, even though large in absolute terms (high-skilled emigration triples in all three Southern countries) has a relatively limited impact on divergence.

Finally, it is instructive to consider the differences between the aggregate and firm-level results. As shown in Table 8, Italy's aggregate growth rate in the baseline calibration represents around 53\% of the German one. However, at the firm level, productivity differences are actually substantially smaller: an IT-adopting Italian firm increases its output per worker by $72 \%$ as much as a German firm ${ }^{36}$ This shows that inferring the aggregate consequences of the IT Revolution directly from reducedform microeconometric regressions (such as the ones shown in Section 2) would be highly misleading. In the context of our model, this would miss the fact that Southern European IT adoption rates are lower, that the IT Revolution increases the aggregate importance of management, and that it stimulates high-skilled emigration. All these margins combined imply that the aggregate divergence is almost twice as large as the firm-level one.

\subsection{Robustness Checks}

Table 9 reports a series of robustness checks around our baseline calibration. As noted before, we rely on US growth accounting data and on our model to calibrate the impact of the IT Revolution on German productivity growth. However, apart from more efficient management practices (which our model takes into account), there are several specificities of the US economy (such as the fact that most major IT producers are American) which could imply that IT had a larger impact in the US than in Germany. Therefore, Row [2] reports our main results when we explicitly impose a German growth target of $8.5 \%$, almost 3 percentage points lower than in the baseline calibration (63\% of the US number instead of $82 \%$ ). We recalibrate the model using the new growth target and otherwise proceed as in our baseline calibration. This more

35. In our model, emigration lowers aggregate productivity because it increases the education costs of the marginal high-skilled worker, but also because love for variety implies that aggregate productivity depends on population size (for empirical evidence on this, see Peters 2017). To assess the relative strength of the two channels, we consider a counterfactual without high-skilled migration, but with exogenous low-skilled emigration, set equal to the emigrant shares in the population shown in Table 8 , both before and after the IT Revolution. Low-skilled emigration lowers productivity growth by roughly half as much as the increase in high-skilled emigration did.

36. For a firm that already uses management, output per worker increases by a factor $\exp \left(\alpha_{2} \varphi_{I T}+\alpha_{3} \xi \varphi_{I T}\right)$ when adopting IT. Thus, firm-level productivity differences are given by $\exp \left(\alpha_{3}\left(\xi^{I T A}-\xi^{D E U}\right) \varphi_{I T}\right)$. 
TABLE 9. Robustness checks.

\begin{tabular}{|c|c|c|c|c|c|c|c|c|c|c|c|}
\hline & \multicolumn{4}{|c|}{ Growth rates } & \multicolumn{3}{|c|}{ Relative growth } & \multicolumn{3}{|c|}{ Diverg. explained } \\
\hline & & DEU & ITA & PRT & ESP & ITA & PRT & ESP & ITA & PRT & ESP \\
\hline$[1]$ & Baseline & $11.1 \%$ & $5.9 \%$ & $3.4 \%$ & $2.5 \%$ & $53 \%$ & $31 \%$ & $23 \%$ & $35 \%$ & $81 \%$ & $47 \%$ \\
\hline [2] & $8.5 \%$ growth in Germany & $8.5 \%$ & $4.6 \%$ & $2.7 \%$ & $2.0 \%$ & $54 \%$ & $32 \%$ & $24 \%$ & $26 \%$ & $61 \%$ & $35 \%$ \\
\hline$[3]$ & $\varepsilon=4$ & $11.8 \%$ & $7.7 \%$ & $5.4 \%$ & $4.4 \%$ & $66 \%$ & $46 \%$ & $37 \%$ & $27 \%$ & $68 \%$ & $40 \%$ \\
\hline [4] & $k=3$ & $11.3 \%$ & $6.4 \%$ & $3.9 \%$ & $3.0 \%$ & $57 \%$ & $35 \%$ & $27 \%$ & $33 \%$ & $78 \%$ & $45 \%$ \\
\hline [5] & $\alpha_{0}=0.13$ & $11.1 \%$ & $5.9 \%$ & $3.4 \%$ & $2.5 \%$ & $53 \%$ & $31 \%$ & $23 \%$ & $35 \%$ & $81 \%$ & $47 \%$ \\
\hline$[6]$ & $\alpha_{0}=0.09$ & $11.1 \%$ & $5.9 \%$ & $3.4 \%$ & $2.5 \%$ & $53 \%$ & $31 \%$ & $23 \%$ & $35 \%$ & $81 \%$ & $47 \%$ \\
\hline [7] & WMS w/o multinationals & $9.5 \%$ & $4.3 \%$ & $1.8 \%$ & $1.3 \%$ & $45 \%$ & $19 \%$ & $14 \%$ & $35 \%$ & $81 \%$ & $44 \%$ \\
\hline [8] & People management & $8.6 \%$ & $4.3 \%$ & $2.2 \%$ & $1.4 \%$ & $50 \%$ & $26 \%$ & $17 \%$ & $29 \%$ & $67 \%$ & $39 \%$ \\
\hline [9] & 40\% IT Empl. share & $10.9 \%$ & $5.5 \%$ & $3.1 \%$ & $2.2 \%$ & $51 \%$ & $28 \%$ & $20 \%$ & $36 \%$ & $83 \%$ & $47 \%$ \\
\hline [10] & 70\% IT Empl. share & $11.4 \%$ & $6.6 \%$ & $4.1 \%$ & $3.1 \%$ & $58 \%$ & $36 \%$ & $27 \%$ & $32 \%$ & $78 \%$ & $45 \%$ \\
\hline [11] & ERP complementarity & $10.0 \%$ & $3.5 \%$ & $1.1 \%$ & $0.4 \%$ & $35 \%$ & $11 \%$ & $4 \%$ & $44 \%$ & $95 \%$ & $53 \%$ \\
\hline [12] & $\alpha_{1}=0.05$ & $11.2 \%$ & $6.1 \%$ & $3.6 \%$ & $2.6 \%$ & $54 \%$ & $32 \%$ & $24 \%$ & $34 \%$ & $81 \%$ & $46 \%$ \\
\hline [13] & Full period (1995-2015) & $13.9 \%$ & $7.5 \%$ & $4.3 \%$ & $3.1 \%$ & $54 \%$ & $31 \%$ & $22 \%$ & $30 \%$ & $68 \%$ & $51 \%$ \\
\hline
\end{tabular}

Note: This table shows the increase in productivity triggered by the IT Revolution, Southern European countries growth rates with respect to Germany, and the share of the empirical divergence with respect to Germany explained by our model for our baseline (row [1]) and twelve alternative parametrizations (rows [2] to [13]). The alternative parametrizations shown in the different rows are described in the main text.

conservative scenario does not change the relative growth rates of Southern European countries: as in our baseline calibration, Italy's growth rate is a little more than half of the German one, and Spain's a little less than a quarter. However, as absolute growth rates are lower, the IT Revolution explains a slightly smaller share of the actually observed productivity divergence: $26 \%$ in Italy, 35\% in Spain and 61\% in Portugal.

In Rows [3] and [4], we change the parameter values that govern the shape of the firm size distribution, namely the elasticity of substitution (increased to $\varepsilon=4$ ) and the shape parameter of the Pareto distribution (lowered to $k=3$ ). Again, all other external parameters are set to their baseline values and the model is recalibrated to the baseline targets. Both changes make the firm size distribution more right-skewed and slightly lower our divergence estimates. Indeed, with a more right-skewed firm size distribution, heterogeneous adoption rates and composition changes matter less, and aggregate divergence estimates become closer to the firm-level estimates discussed in the previous section. In the extreme case in which production were carried out by one single firm and there were no migration, they would coincide.

Rows [5] to [8] report a line of robustness checks for management scores. In our baseline calibration, we set the management score of firms producing with the basic technology to -1.11 , and therefore $\alpha_{0}$ to 0.111 . In Rows [5] and [6], we increase 
or decrease this baseline number, showing that this hardly affects our estimates. In Rows [7] and [8], we instead use different types of management scores to calibrate our model. Row [7] uses management scores that ignore multinational firms and control for cross-country differences in sample selection, as provided in Bloom et al. (2016, Table 7). Row [8] replaces the general management score by the sub-score for "people management", which has been shown to be particularly important for the interaction with IT (Bloom et al. 2012). Neither of these two alternatives changes our results substantially.

Rows [9] to [12] report robustness checks on the IT calibration. Rows [9] and [10] consider different targets for the employment share of IT-using German firms, showing that this hardly changes our baseline results. In Row [11], we consider the value for the parameter $\alpha_{3}$ implied by our estimates for ERP software in Table 2, $\alpha_{3}=2.382$. This estimate is substantially higher than the one used in our baseline parametrization. As $\alpha_{3}$ captures the degree of management-IT complementarity, this higher value obviously implies a higher divergence estimate, but nevertheless, magnitudes remain comparable. In Row [12], we set $\alpha_{1}=0.05$, that is, we assume that the direct effect of management on productivity is lower than in the baseline.

Finally, in Row [13], we report our results for a calibration for the full period 19952015 (described in greater detail in Online Appendix B). These results are very similar to our baseline estimates for the shorter period 1995-2008, with the share of divergence explained by our model being somewhat smaller in Italy and Portugal, and somewhat larger in Spain.

Overall, our results suggest that the IT Revolution can explain a sizeable part of Southern Europe's divergence with respect to Germany between 1995 and 2008. Across different parametrizations, it accounts for 26 to $36 \%$ of Italy's divergence, 35 to $47 \%$ of Spain's divergence, and 61 to $83 \%$ of Portugal's divergence.

\section{Counterfactual Policy Experiments}

In this section, we analyse the effects of policies which could potentially reduce the productivity divergence induced by the IT Revolution. We consider a range of policy measures that are frequently discussed or even implemented in reality, such as IT subsidies, education subsidies or policies facilitating cross-border M\&As. Throughout, we assume that these policies are only implemented in Southern Europe, in order to check whether they successfully reduce the gap with the North.

\subsection{IT and Management Adoption Subsidies}

In our model and in the data, Southern European countries have lower IT adoption rates than Northern ones. Therefore, it seems natural that governments would try to reduce 
TABLE 10. The effect of subsidies for IT and management adoption.

\begin{tabular}{lccc|ccc}
\hline & \multicolumn{3}{c}{ IT subsidy } & \multicolumn{3}{c}{ Management subsidy } \\
& Italy & Portugal & Spain & Italy & Portugal & Spain \\
\hline Tax revenue (\% of national income) & $1 \%$ & $1 \%$ & $1 \%$ & $1 \%$ & $1 \%$ & $1 \%$ \\
$\tau_{M}$ & 0 & 0 & 0 & $42 \%$ & $48 \%$ & $51 \%$ \\
$\tau_{I T}$ & $27 \%$ & $36 \%$ & $41 \%$ & 0 & 0 & 0 \\
Change in productivity & $-0.32 \%$ & $-0.43 \%$ & $-0.51 \%$ & $-0.52 \%$ & $-0.61 \%$ & $-0.67 \%$ \\
Change in empl. share of firms with mgmt & $+2 \mathrm{pp}$ & $+2 \mathrm{pp}$ & $+2 \mathrm{pp}$ & $+13 \mathrm{pp}$ & $+15 \mathrm{pp}$ & $+16 \mathrm{pp}$ \\
Change in empl. share of firms with IT & $+8 \mathrm{pp}$ & $+9 \mathrm{pp}$ & $+9 \mathrm{pp}$ & $-2 \mathrm{pp}$ & $-1 \mathrm{pp}$ & $-1 \mathrm{pp}$ \\
Change in net high-skilled wages & $+0.7 \%$ & $+0.6 \%$ & $+0.5 \%$ & $+0.6 \%$ & $+0.5 \%$ & $+0.5 \%$ \\
Change in net low-skilled wages & $-0.6 \%$ & $-0.7 \%$ & $-0.8 \%$ & $-0.8 \%$ & $-0.9 \%$ & $-1.0 \%$ \\
Change in emigration & $-20 \%$ & $-13 \%$ & $-11 \%$ & $-18 \%$ & $-12 \%$ & $-10 \%$ \\
\hline
\end{tabular}

Note: All changes are with respect to the equilibrium with IT in our baseline calibration, shown in Table 8 Except for $\tau_{I T}$ and $\tau_{M}$, all parameter values are the same as in this baseline calibration. Productivity is measured as output per worker. The change in emigration refers to the percentage change in the absolute number of emigrants.

this gap by subsidizing IT adoption. IT subsidies are indeed a common industrial policy tool ${ }^{37}$ What would be the impact of such subsidies in our model?

To answer this question, we extend our model to include a government which levies a proportional tax on wages and uses it to finance an IT adoption subsidy $\tau_{I T}$, reducing firms' effective fixed cost of IT adoption to $\left(1-\tau_{I T}\right) f_{I T} w_{H}^{S}$. The extended model is fully developed in Online Appendix B.5. Table 10 shows the outcome of the policy, calibrated so that tax revenue represents $1 \%$ of national income.

The ensuing IT subsidy is large (covering between 27 and $41 \%$ of firms' adoption costs), and indeed increases IT adoption: the employment share of firms using IT increases by almost 10 percentage points in all countries. However, the policy actually reduces aggregate productivity by $0.32 \%$ in Italy, and by $0.51 \%$ in Spain. Furthermore, it has a strong effect on the income distribution: as it stimulates the demand for high-skilled workers, it leads to a increase in the net high-skilled wage (and a fall in emigration), whereas net low-skilled wages fall.

We also consider a similar experiment with a management adoption subsidy $\tau_{M}$ (reducing firms' effective cost of management adoption to $\left(1-\tau_{M}\right) f_{M} w_{H}^{S}$ ), calibrated to correspond to the same share of tax revenue in national income. This subsidy has an even worse effect on aggregate productivity. Redistributive effects are similar to the IT subsidy, but the increase in high-skilled wages is now smaller, and

37. For example, Italy introduced in 2016 a generous tax credit for capital investments related to "Industry 4.0 ", aimed at digitalization, automation and data exchange for production in manufacturing. While there is yet no official data on take-up rates, anecdotal evidence suggest that they are substantial. 
the decrease in low-skilled wages is stronger. Management adoption increases, but IT adoption falls, because the higher skill premium makes adoption less attractive.

The fact that adoption subsidies reduce output and productivity is not surprising. Indeed, there are no externalities or distortions in our model ${ }^{38}$ Thus, the market allocation of resources is optimal, and subsidies inefficiently distort it. Of course, in the presence of externalities and spillovers, which may be important for some IT technologies in the real world, subsidies would be useful again. Thus, our policy simulations should be taken with a grain of salt. Nevertheless, they do stress a key implication of our analysis: low IT adoption is a symptom of Southern European problems rather than the problem in itself. Thus, while subsidizing IT adoption will certainly reduce the delay in IT diffusion with respect to other advanced economies, the aggregate effects of such a policy will be limited, if not reversed, by managementIT complementarities.

\subsection{Education Subsidies}

Alternatively, we consider subsidies to education. Precisely, we assume that the government levies a lump-sum tax $t$ on wages and uses the proceeds to pay a lumpsum subsidy $s$ to all workers that become high-skilled. This can be interpreted as the equivalent of real-world subsidies such as free higher education, government-provided scholarships or subsidies for student loans. Details on this model are presented in Online Appendix B.5.

Table 11 shows the impact of the subsidy, calibrated such that the lump-sum tax represents $5 \%$ of the wage of low-skilled workers. This subsidy does not improve Southern Europe's situation: even though the high-skilled share of the workforce increases, output per capita decreases. Furthermore, as the policy directly redistributes resources from low to high-wage workers, it is regressive. The most noticeable effect of the policy is a large increase in emigration of high-skilled workers, which triples in Italy and more than doubles in Portugal and Spain. This suggests that in the presence of worker mobility, subsidizing education in the South may effectively only result in a transfer to the North, which benefits from the emigration of workers educated in the South.

Alternatively, the education subsidy could be limited to workers that do not emigrate ${ }^{39}$ Table 11 shows that this would somewhat improve its impact on aggregate productivity, as migration would now be roughly unchanged ${ }^{40}$ Yet, the overall effect

38. To be precise, there is one distortion, namely the monopoly power of firms. However, because all firms charge the same markup and labour supply is inelastic, this has no effect on aggregate output.

39. A policy of this type could be implemented by granting a temporary income tax exemption after graduation. Italy has a policy of this type for high-skilled foreign residents that choose to move to Italy: these pay income tax only on a fraction of their income (from $10 \%$ for researchers to $50 \%$ for graduates in general) during four years.

40. With conditional subsidies, high-skilled emigration is driven by two effects. On the one hand, the increasing supply of high-skilled labour lowers the high-skilled wage in the South, and increases the 
TABLE 11. The effect of education subsidies

\begin{tabular}{|c|c|c|c|c|c|c|}
\hline \multirow[t]{2}{*}{ Beneficiaries of the subsidy } & \multicolumn{3}{|c|}{ All high-skilled workers } & \multicolumn{3}{|c|}{ Non-emigrants only } \\
\hline & Italy & Portugal & Spain & Italy & Portugal & Spain \\
\hline Tax (\% of low-skilled wage) & $5 \%$ & $5 \%$ & $5 \%$ & $5 \%$ & $5 \%$ & $5 \%$ \\
\hline Subsidy ( $\%$ of high-skilled wage) & $17 \%$ & $18 \%$ & $19 \%$ & $18 \%$ & $19 \%$ & $19 \%$ \\
\hline Change in productivity & $-0.88 \%$ & $-0.91 \%$ & $-0.93 \%$ & $-0.58 \%$ & $-0.61 \%$ & $-0.62 \%$ \\
\hline Change in the share of high-skilled workers & $+4 \mathrm{pp}$ & $+4 \mathrm{pp}$ & $+4 \mathrm{pp}$ & $+4 \mathrm{pp}$ & $+4 \mathrm{pp}$ & $+4 \mathrm{pp}$ \\
\hline Change in net high-skilled wages & $-0.4 \%$ & $-0.5 \%$ & $-0.5 \%$ & $-0.3 \%$ & $-0.4 \%$ & $-0.5 \%$ \\
\hline Change in net low-skilled wages & $-1.7 \%$ & $-1.7 \%$ & $-1.7 \%$ & $-1.3 \%$ & $-1.3 \%$ & $-1.3 \%$ \\
\hline Change in emigration & $+200 \%$ & $+138 \%$ & $+125 \%$ & $+4 \%$ & $+3 \%$ & $+3 \%$ \\
\hline
\end{tabular}

Note: All changes are with respect to the equilibrium with IT in our baseline calibration, shown in Table 8 Except for $t$ and $s$, all parameter values are the same as in this baseline calibration. Subsidies for high-skilled workers are stated net of taxes. Productivity is measured as output per worker. The change in emigration refers to the percentage change in the absolute number of emigrants.

remains negative, for the same reason as for the IT and management subsidies: the education choices of Southern European workers were optimal to start with and the subsidy distorted them.

Overall, these counterfactuals illustrate that subsidy policies do not improve Southern Europe's situation in our model. This is due to the fact that such policies only attack the symptoms of the problem. Instead, in order to succeed, policies need to directly address the "disease", worse management practices ${ }^{41}$ In the next subsections, we discuss such policies.

\subsection{Subsidiaries of Foreign Multinationals}

Recent empirical evidence suggests that the presence of foreign multinationals can improve a country's management practices. These effects are both direct, as subsidiaries may inherit the superior management practices of their parents (Bloom et al.2012), and indirect, as best practices may spill over to surrounding firms through manager mobility or other channels (Bloom et al.2018).

incentives for emigration. On the other hand, the subsidy, which can only be perceived when staying in the South, decreases the incentives for emigration. Table 11 shows that the net effect of the policy is a slight decrease of the Southern net high-skilled wage (after subsidies), and therefore a slight increase in emigration.

41. In particular, note that the education subsidies just analysed neither change the social cost nor the quality of education. Policies that improve education quality may of course reduce Southern Europe's divergence, especially if they increase the human capital of managers and thereby improve management practices. 
TABLE 12. Multinational firms and transfers of management practices.

\begin{tabular}{lccccccccc}
\hline No spillovers & \multicolumn{3}{c}{ Italy } & \multicolumn{3}{c}{ Portugal } & & \multicolumn{2}{c}{ Spain } \\
\hline$f_{F D I}$ & $+\infty$ & 50 & 5 & $+\infty$ & 50 & 5 & $+\infty$ & 50 & 5 \\
\hline Emp. share of multinat. & $0.00 \%$ & $4.4 \%$ & $19.3 \%$ & $0.00 \%$ & $6.6 \%$ & $27.6 \%$ & $0.00 \%$ & $7.5 \%$ & $30.8 \%$ \\
Rel. Productivity w.r. to Germany & 0.934 & 0.938 & 0.950 & 0.902 & 0.910 & 0.937 & 0.890 & 0.901 & 0.935 \\
Emp. share of firms with IT & $36.3 \%$ & $36.9 \%$ & $38.7 \%$ & $27.5 \%$ & $28.9 \%$ & $33.4 \%$ & $23.5 \%$ & $25.5 \%$ & $31.6 \%$ \\
Emigrants (\% of high-skilled) & $0.84 \%$ & $0.79 \%$ & $0.61 \%$ & $1.35 \%$ & $1.21 \%$ & $0.80 \%$ & $1.56 \%$ & $1.38 \%$ & $0.84 \%$ \\
& & & & & & & & & \\
\hline Spillovers & & Italy & & & Portugal & & & Spain & \\
\hline$f_{F D I}$ & $+\infty$ & 50 & 5 & $+\infty$ & 50 & 5 & $+\infty$ & 50 & 5 \\
\hline Emp. share of multinat. & $0.00 \%$ & $4.3 \%$ & $16.8 \%$ & $0.00 \%$ & $6.2 \%$ & $23.0 \%$ & $0.00 \%$ & $7.1 \%$ & $25.3 \%$ \\
Rel. Productivity w.r. to Germany & 0.934 & 0.940 & 0.956 & 0.902 & 0.914 & 0.943 & 0.890 & 0.905 & 0.940 \\
Emp. share of firms with IT & $36.3 \%$ & $37.5 \%$ & $40.3 \%$ & $27.5 \%$ & $30.1 \%$ & $36.3 \%$ & $23.5 \%$ & $27.1 \%$ & $34.8 \%$ \\
Emigrants (\% of high-skilled) & $0.84 \%$ & $0.76 \%$ & $0.54 \%$ & $1.35 \%$ & $1.15 \%$ & $0.71 \%$ & $1.56 \%$ & $1.30 \%$ & $0.76 \%$ \\
\hline
\end{tabular}

Note: This table illustrates the equilibrium of our extended model for different levels of the fixed cost of becoming a multinational subsidiary $f_{F D I}$. All other parameter values are the same as in the baseline calibration. Thus, the equilibrium for $f_{F D I} \rightarrow+\infty$ corresponds to the baseline shown in Table 8

To quantify the potential effects of greater multinational presence in Southern Europe, we consider an extension of our model in which we assume that Southern firms can pay an additional fixed cost of $f_{F D I}$ units of high-skilled labour in order to upgrade their management practices to the Northern level. The firms making this choice can be interpreted as subsidiaries of Northern multinationals, with the fixed cost $f_{F D I}$ representing the cost multinationals have to pay to establish a subsidiary ${ }^{42}$ The extended model is presented in greater detail in Section B.6 of the online appendix.

Table 12 illustrates the potential difference that these firms can make. We consider two different scenarios, corresponding to two different values for the fixed cost $f_{F D I}$ : a high one, which delivers an employment share of subsidiaries of around $5 \%$ in the average Southern country, and a low one, which delivers a share of $25 \%$. All other parameters are set to their baseline calibration values. The productivity effects are large: in the most optimistic scenario, the presence of subsidiaries increases productivity by $1.7 \%$ in Italy, 3.9\% in Portugal and 5.1\% in Spain, filling a substantial part of the productivity gap with respect to Germany. Furthermore, the presence of these firms lowers the emigration rates of high-skilled workers by between 25 and $50 \%$.

42. Obviously, subsidiaries of multinationals are already present in all advanced economies. In our baseline model, we did not consider them explicitly, as we assumed that all firms within a country have the same management practices. However, note that the management scores in our calibration are computed using data from both domestic firms and multinationals. Therefore, the $\xi$ parameter used in our baseline calibration does account for the actual presence of multinationals, and one should think of the exercise in this section as simulating a further increase in their presence. 
Next, we allow for spillovers, assuming that the presence of subsidiaries increases management scores of Southern domestic firms to a weighted average of $\xi^{S}$ and $\xi^{N}$, where the weights are given by the employment shares of firms operating with both types of management practices. This is in line with the idea that, in the presence of manager turnover, former managers of firms with good management practices could transfer their knowledge to their subsequent employers (Bloom et al.,2018; Serafinelli] 2018). Spillovers increases productivity even further, and in the most optimistic scenario, they fill around 33\% of the Italian and $45 \%$ of the Spanish productivity gap with respect to Germany.

These results suggest that welcoming foreign ownership may improve Southern Europe's management practices. However, they obviously depend on the assumption that management practices are transferable across countries. Depending on the exact determinants of Southern Europe's management problems, this may not be the case. In the next section, we discuss these determinants (and ways to improve them) in greater detail.

\subsection{Improving Management Practices}

Policies aiming to improve management practices will in general need to tackle the factors that render management inefficient in the first place. However, as we discussed in Section 2.4, researchers have only recently started to analyse these determinants, stressing factors such as human capital, judicial institutions, competition, labour and product market regulation, trust and family values. In this subsection, we review some insights of this literature, and offer some tentative reflections on their policy implications.

Bloom et al. (2018) use data from 35.000 US manufacturing plants collected through a new ad-hoc survey of the US Census Bureau. They show that a more business-friendly environment, as measured by Right-to-Work laws, improves practices associated with human resources management. This coincides with a common emphasis in policy circles about the need for Southern Europe to undertake "structural reforms" to improve the business environment. In this respect, it is important to stress that Southern European countries have actually significant reformed their labour market regulation, as shown by the OECD 2013 Employment outlook (see OECD 2013, pp. 93). It will be interesting for future research to assess if these reforms translate into better management practices.

Another factor often emphasized in the literature is the ownership structure of firms. A range of recent papers show that family-managed firms have worse management practices than firms run by professional managers ${ }^{43}$ Furthermore, it is

43. Lippi and Schivardi (2014) and Bandiera et al. (2015) show that, compared to other ownership modes, family firms tend to select managers on the basis of loyalty rather than skills, thus reducing the quality of the managerial pool. Bennedsen et al. (2007) supply causal evidence that, upon succession, firms appointing a family CEO record a worse performance than those choosing an external CEO. Lemos and Scur (2019) show that the lower performance can be traced back to worse management practices resulting from dynastic 
well-known that family-managed firms are more prevalent in Southern than in Northern Europe (see Bugamelli et al. 2012). While the reasons for this prevalence of family firms in the South are still not fully understood, our simple microfoundation for management efficiency, laid out in Section B.2 in the online appendix, suggests that the efficiency of the court system and personal values could play a role. Inefficient courts increase the agency costs between owners and external managers, and therefore make it more likely that owners select managers within the narrow family circle. Furthermore, even if firms continue to hire external managers, the higher monitoring costs associated with inefficient courts constitute a drag on efficiency.

As we show in greater detail in Section B.2 in the online appendix, the data is consistent with this narrative. The World Value Survey shows that respondents in Southern Europe are both more likely to trust family members and less likely to trust strangers than respondents in Northern Europe. The World Bank's "Doing Business" report in turn shows that in Italy, Spain and Portugal, courts take significantly longer to make decisions, and the quality of these decisions is worse than in Northern European countries. This suggests that improving Southern Europe's judicial system could potentially improve corporate governance and therefore management practices.

\section{Conclusions}

Southern Europe's recent slowdown in productivity growth and the ensuing divergence with the rest of the OECD can be partially explained by the interaction between the IT Revolution and the inefficient management practices of Southern European firms. Indeed, we have argued in this paper that the appearance of IT, which has strong complementarities with management practices, stimulated income and productivity growth in Southern Europe less than in other countries. Our quantitative analysis suggests that across different countries and parametrizations considered, this mechanism can explain more than one third of the aggregate productivity divergence of Southern Europe with respect to Germany between 1995 and 2008. This result is driven by differences in adoption rates, differences in firm-level productivity gains, and the increase in the aggregate importance of management. Divergence has also amplified the emigration of high-skilled workers from the South.

One important question for future productivity developments is whether technological progress will remain "management-biased". A recent literature has emphasized the growing importance of intangible capital for productivity growth (see, e.g., Corrado et al. 2016), particularly related to new developments for Artificial Intelligence and Machine Learning (Brynjolfsson et al.2018a). This literature suggests that just like IT, these technological developments are likely to be complementary to skill and management practices. If this is the case, the productivity divergence observed over the last two decades might well worsen in the future.

CEO successions. Finally, Bloom and Van Reenen (2007) show that family-managed firms tend to have lower scores in the World Management Survey. 
Summing up, our research indicates that in order to fully realize the potential of IT and other new technologies, to reduce the productivity gap and to retain their most talented workers, Southern European countries need to solve their management problems. Our results show that the gains from improving management are large. Thus, uncovering the deep determinants of differences in management efficiency across countries is a very important topic for future research.

\section{References}

Akcigit, Ufuk, Harun Alp, and Michael Peters (2016). "Lack of Selection and Limits to Delegation: Firm Dynamics in Developing Countries.” NBER Working Paper 21905, National Bureau of Economic Research, Inc, URL https://ideas.repec.org/p/nbr/nberwo/21905.html

Akerman, Anders, Ingvil Gaarder, and Magne Mogstad (2015). "The Skill Complementarity of Broadband Internet.” The Quarterly Journal of Economics, 130(4), 1781-1824.

Anelli, Massimo, Gaetano Basso, Giuseppe Ippedico, and Giovanni Peri (2017). "The Costs of Youth Drain." Mimeo.

Anelli, Massimo and Giovanni Peri (2017). "Does emigration delay political change? Evidence from Italy during the Great Recession." Economic Policy, 32(91), 551-596.

Arkolakis, Costas (2010). "Market Penetration Costs and the New Consumers Margin in International Trade." Journal of Political Economy, 118(6), 1151-1199.

Bandiera, Oriana, Luigi Guiso, Andrea Prat, and Raffaella Sadun (2015). "Matching firms, managers, and incentives." Journal of Labor Economics, 33(3), 623-681.

Bartelsman, Eric, Stefano Scarpetta, and Fabiano Schivardi (2005). "Comparative analysis of firm demographics and survival: evidence from micro-level sources in OECD countries." Industrial and Corporate Change, 14(3), 365-391.

Basu, Susanto and John G. Fernald (2008). "Information and communications technology as a general purpose technology: evidence from U.S. industry data." Economic Review, pp. 1-15.

Bayo-Moriones, Alberto and Fernando Lera-López (2007). "A firm-level analysis of determinants of ICT adoption in Spain.” Technovation, 27(6), 352-366.

Becker, Sascha O., Andrea Ichino, and Giovanni Peri (2004). "How large is the "Brain Drain" from Italy?" Giornale degli Economisti e Annali di Economia, 63 (Anno 117)(1), 1-32.

Bennedsen, Morten, Kasper Meisner Nielsen, Francisco Pérez-González, and Daniel Wolfenzon (2007). "Inside the family firm: The role of families in succession decisions and performance." The Quarterly Journal of Economics, 122(2), 647-691.

Bloom, Nicholas, Erik Brynjolfsson, Lucia Foster, Ron S Jarmin, Megha Patnaik, Itay SaportaEksten, and John Van Reenen (2018). "What Drives Differences in Management?" American Economic Review. Forthcoming.

Bloom, Nicholas, Benn Eifert, Aprajit Mahajan, David McKenzie, and John Roberts (2013). "Does Management Matter? Evidence from India." The Quarterly Journal of Economics, 128(1), 1-51.

Bloom, Nicholas, Raffaella Sadun, and John Van Reenen (2012). "Americans Do IT Better: US Multinationals and the Productivity Miracle." American Economic Review, 102(1), 167-201.

Bloom, Nicholas, Raffaella Sadun, and John Van Reenen (2016). "Management as a Technology?" NBER Working Paper 22327, National Bureau of Economic Research, Inc, URL https://ideas. repec.org/p/nbr/nberwo/22327.html

Bloom, Nicholas and John Van Reenen (2007). "Measuring and Explaining Management Practices Across Firms and Countries." The Quarterly Journal of Economics, (122), 1351-1408.

Bresnahan, T., E. Brynjolfsson, and L. Hitt (2002). "Information Technology, Workplace Organization, and the Demand for Skilled Labor: Firm-Level Evidence.” Quarterly Journal of Economics, 117, 339-376. 
Bruhn, Miriam, Dean Karlan, and Antoinette Schoar (2018). "The Impact of Consulting Services on Small and Medium Enterprises: Evidence from a Randomized Trial in Mexico." Journal of Political Economy, 126(2), 635-687.

Brynjolfsson, Erik and Lorin M. Hitt (2000). "Beyond Computation: Information Technology, Organizational Transformation and Business Performance." Journal of Economic Perspectives, 14(4), 23-48.

Brynjolfsson, Erik, Daniel Rock, and Chad Syverson (2018a). "Artificial intelligence and the modern productivity paradox: A clash of expectations and statistics." In The Economics of Artificial Intelligence: An Agenda, edited by Ajay Agrawal, Joshua Gans, and Avi Goldfarb. University of Chicago Press.

Brynjolfsson, Erik, Daniel Rock, and Chad Syverson (2018b). "The Productivity J-Curve: How Intangibles Complement General Purpose Technologies.” NBER Working Papers 25148, National Bureau of Economic Research, Inc.

Bugamelli, Matteo, Luigi Cannari, Francesca Lotti, and Silvia Magri (2012). "The innovation gap of Italy's production system: roots and possible solutions.” Bank of Italy Occasional Paper 121.

Bustos, Paula (2011). "Trade Liberalization, Exports, and Technology Upgrading: Evidence on the Impact of MERCOSUR on Argentinian Firms." American Economic Review, 101(1), 304-40.

Byrne, David M., Stephen D. Oliner, and Daniel E. Sichel (2013). "Is the Information Technology Revolution Over?" International Productivity Monitor, 25, 20-36.

Calligaris, Sara (2015). "Misallocation and Total Factor Productivity in Italy: Evidence from FirmLevel Data." CEIS Research Paper 357, Tor Vergata University, CEIS, URL https://ideas.repec. org/p/rtv/ceisrp/357.html

Calligaris, Sara, Massimo Del Gatto, Fadi Hassan, Gianmarco I.P. Ottaviano, and Fabiano Schivardi (2016). "Italy's Productivity Conundrum. A Study on Resource Misallocation in Italy.” European Economy - Discussion Papers 2015 - 030, Directorate General Economic and Financial Affairs (DG ECFIN), European Commission, URL https://ideas.repec.org/p/euf/dispap/030.html

Chaney, Thomas (2008). "Distorted Gravity: The Intensive and Extensive Margins of International Trade." American Economic Review, 98(4), 1707-21.

Corrado, Carol, Jonathan Haskel, Cecilia Jona-Lasinio, and Massimiliano Iommi (2016). "Intangible investment in the EU and US before and since the Great Recession and its contribution to productivity growth.” Tech. rep., EIB Working Papers.

Daveri, Francesco and Maria Laura Parisi (2010). "Experience, Innovation and Productivity Empirical Evidence from Italy's Slowdown.” CESifo Working Paper Series 3123, CESifo Group Munich, URL https://ideas.repec.org/p/ces/ceswps/_3123.html

Fabiani, Silvia, Fabiano Schivardi, and Sandro Trento (2005). "ICT adoption in Italian manufacturing: firm-level evidence." Industrial and Corporate Change, 14(2), 225-249.

Fackler, Daniel, Claus Schnabel, and Joachim Wagner (2013). "Establishment exits in Germany: the role of size and age." Small Business Economics, 41(3), 683-700.

Fernald, John (2014). "Productivity and Potential Output Before, During, and After the Great Recession.” In NBER Macroeconomics Annual 2014, Volume 29.

Garcia-Santana, Manuel, Enrique Moral-Benito, Josep Pijoan-Mas, and Roberto Ramos (2015). "Growing like Spain: 1995-2007." Mimeo.

Garicano, Luis (2015). "Can slow IT adoption explain productivity slowdown? Firm size and organizational change.” Presentation to CompNet-ECB Workshop, Madrid.

Garicano, Luis and Paul Heaton (2010). "Information Technology, Organization, and Productivity in the Public Sector: Evidence from Police Departments.” Journal of Labor Economics, 28(1), 167-201.

Garicano, Luis, Claire Lelarge, and John Van Reenen (2016). "Firm size distortions and the productivity distribution: Evidence from France." The American Economic Review, 106(11), 3439-3479.

Geerolf, Francois (2017). “A Theory of Pareto Distributions.” Mimeo. 
Giorcelli, Michela (2016). "The Long-Term Effects of Management and Technology Transfer: Evidence from the US Productivity Program." Mimeo.

Gopinath, Gita, Sebnem Kalemli-Ozcan, Loukas Karabarbounis, and Carolina Villegas-Sanchez (2017). "Capital Allocation and Productivity in South Europe." The Quarterly Journal of Economics, 132(4), 1915-1967.

Gordon, Robert J. (2016). The Rise and Fall of American Growth: The U.S. Standard of Living since the Civil War. Princeton University Press.

Guiso, Luigi, Luigi Pistaferri, and Fabiano Schivardi (2015). "Learning Entrepreneurship From Other Entrepreneurs?" Working Paper 21775, National Bureau of Economic Research, URL http://www.nber.org/papers/w21775

Guner, Nezih, Andrii Parkhomenko, and Gustavo Ventura (2015). "Managers and Productivity Differences." IZA Discussion Papers 9586, Institute for the Study of Labor (IZA), URL https: //ideas.repec.org/p/iza/izadps/dp9586.html

Hsieh, Chang-Tai and Peter J. Klenow (2009). "Misallocation and Manufacturing TFP in China and India." The Quarterly Journal of Economics, 124(4), 1403-1448.

Izquierdo, Mario, Juan F. Jimeno, and Aitor Lacuesta (2015). "Spain: From Immigration To Emigration?" Working Paper 1503, Banco de España, URL https://ideas.repec.org/p/bde/wpaper/ 1503.html

Jones, Charles I. (2011). "Intermediate Goods and Weak Links in the Theory of Economic Development.” American Economic Journal: Macroeconomics, 3(2), 1-28.

Lemos, Renata and Daniela Scur (2019). "The ties that bind: Family CEOs, management practices and firing costs." Mimeo.

Lippi, Francesco and Fabiano Schivardi (2014). "Corporate control and executive selection." Quantitative Economics, 5(2), 417-456.

Melitz, Marc J. (2003). "The Impact of Trade on Intra-Industry Reallocations and Aggregate Industry Productivity." Econometrica, 71(6), 1695-1725.

Melitz, Marc J. and Stephen J. Redding (2014). "Heterogeneous Firms and Trade." In Handbook of International Economics, Handbook of International Economics, vol. 4, edited by Elhanan Helpman Gita Gopinath and Kenneth Rogoff, pp. 1 - 54. Elsevier, URL http://www. sciencedirect.com/science/article/pii/B978044454314100001X

Melitz, Marc J. and Stephen J. Redding (2015). "New Trade Models, New Welfare Implications." American Economic Review, 105(3), 1105-46.

OECD (2013). “Employment Outlook 2013.” Tech. rep., Organization for Economic Cooperation and Development.

Pellegrino, Bruno and Luigi Zingales (2017). "Diagnosing the Italian Disease.” Working Paper 23964, National Bureau of Economic Research, URL http://www.nber.org/papers/w23964.

Peters, Michael (2017). "Refugees and Local Agglomeration - Evidence from Germany's Post-War Population Expulsions." Mimeo.

Schivardi, Fabiano and Roberto Torrini (2008). "Identifying the effects of firing restrictions through size-contingent differences in regulation." Labour Economics, 15(3), 482-511.

Serafinelli, Michel (2018). "'Good' Firms, Worker Flows and Local Productivity.” Journal of Labor Economics. Forthcoming.

Solow, Robert M. (1987). “We'd Better Watch Out.” The New York Times Book Review.

Stiroh, Kevin J. (2002). "Information Technology and the U.S. Productivity Revival: What Do the Industry Data Say?” American Economic Review, 92(5), 1559-1576.

Syverson, Chad (2011). "What Determines Productivity?" Journal of Economic Literature, 49(2), 326-365.

Wozniak, Abigail (2010). “Are College Graduates More Responsive to Distant Labor Market Opportunities?” Journal of Human Resources, 45(4), 944-970. 